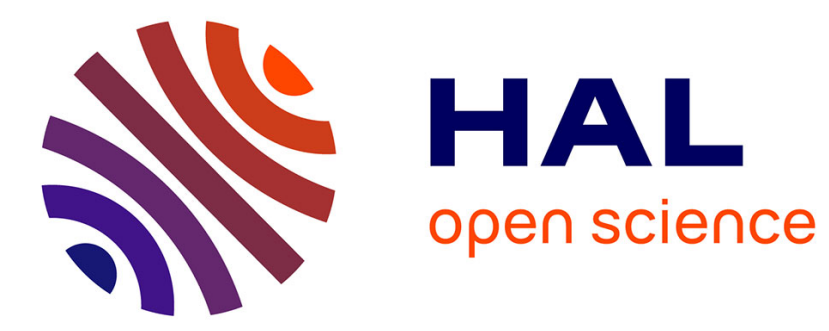

\title{
The 3-D Structure of Mesoscale Eddies in the Lofoten Basin of the Norwegian Sea: A Composite Analysis From Altimetry and In Situ Data
}

\author{
Nikita Sandalyuk, Anthony Bosse, Tatyana Belonenko
}

\section{To cite this version:}

Nikita Sandalyuk, Anthony Bosse, Tatyana Belonenko. The 3-D Structure of Mesoscale Eddies in the Lofoten Basin of the Norwegian Sea: A Composite Analysis From Altimetry and In Situ Data. Journal of Geophysical Research. Oceans, 2020, 125 (10), pp.e2020JC016331. 10.1029/2020JC016331 . hal02968293

\section{HAL Id: hal-02968293 \\ https://hal.science/hal-02968293}

Submitted on 24 Feb 2021

HAL is a multi-disciplinary open access archive for the deposit and dissemination of scientific research documents, whether they are published or not. The documents may come from teaching and research institutions in France or abroad, or from public or private research centers.
L'archive ouverte pluridisciplinaire HAL, est destinée au dépôt et à la diffusion de documents scientifiques de niveau recherche, publiés ou non, émanant des établissements d'enseignement et de recherche français ou étrangers, des laboratoires publics ou privés. 
Sandalyuk NIkita (Orcid ID: 0000-0001-6432-0722)

Bosse Anthony (Orcid ID: 0000-0001-6968-3805)

\section{The 3D structure of Mesoscale Eddies in the Lofoten Basin of the} Norwegian Sea: A composite analysis from altimetry and in situ data

\section{Nikita V. Sandalyuk ${ }^{1 *}$, Anthony Bosse ${ }^{2.3}$, Tatyana V. Belonenko ${ }^{1}$}

${ }^{1}$ Saint Petersburg State University, Saint Petersburg, Russia

${ }^{2}$ Geophysical Institute, University of Bergen and Bjerknes Center for Climate Research, Bergen, Norway

${ }^{3}$ Now at Aix-Marseille Univ., Université de Toulon, CNRS, IRD, MIO UM 110, Marseille, France

Corresponding author: Nikita Sandalyuk (nikitasandaliuk@gmail.com)

\section{Key Points:}

- 3D structure of mesoscale eddies in the Lofoten Basin were revealed by combining the altimetry data and CTD profiles from the multiple platforms

- Significant eddy-induced anomalies are concentrated within the zero vorticity radius and vertically to the depth of $\sim 900-1000 \mathrm{~m}$

- Eddy-induced transport is generally westward emerging from the Norwegian Atlantic Slope Current

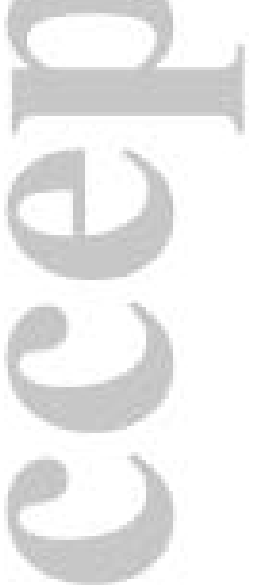

This article has been accepted for publication and undergone full peer review but has not been through the copyediting, typesetting, pagination and proofreading process which may lead to differences between this version and the Version of Record. Please cite this article as doi: 10.1029/2020JC016331 


\section{Abstract}

In this research temperature and salinity profiles in eddy-centered coordinates obtained from satellite altimetry (eddy dataset distributed by AVISO+) are combined to document the mean three-dimensional structures of cyclonic (CEs) and anticyclonic (AEs) eddies in the Lofoten Basin. For eddies of both polarities, significant eddy-induced anomalies are concentrated within the zero vorticity radius and vertically to the depth of $\sim 900-1000 \mathrm{~m}$. The thermohaline vertical structures of CEs and AEs differ in terms of salinity and temperature anomalies. Horizontal structure of the mesoscale eddies showed warmer and saltier anomalies for AEs from the southwest to the northeast side, as well as colder and less salty anomalies from their southeast side for the CEs. This reflects the main features of the basin-scale temperature and salinity gradients, strongly affected by the Norwegian Atlantic Slope Current. Mean zonal eddy-induced transport of volume, heat, and salt is generally westward, consistent with the key role played by eddies generated by the Norwegian Atlantic Slope Current. The obtained results highlight the significant role played by mesoscale eddies in the oceanic circulation of the Lofoten Basin, as well as on heat and salt budgets of a key region for air-sea exchanges, water mass transformation, and climate.

\section{Plain Language Summary}

Mesoscale eddies trap water and transport momentum, volume, heat, salt, and biogeochemical constituents from their generation to dissipation sites. Thus, a detailed understanding of mesoscale eddies is crucial to assess dynamic, climatic, and biological processes in the global Ocean. Here, we investigate three-dimensional structures of mesoscale eddies in the Lofoten Basin (Nordic Seas) by combining the satellite and temperature and salinity data from the multiple platforms (research vessels, autonomous profiling floats and gliders). We could estimate the heat and salt transport by cyclonic and anticyclonic eddies. The results highlight the significant role played by mesoscale eddies in the oceanic circulation of the Lofoten Basin, as well as on heat and salt budgets of this important region for air-sea exchanges, water mass transformation and climate implications. The obtained three-dimensional structures can also be used as a base for the future estimation of the impact of mesoscale eddies on the biogeochemical processes and environment in the LB region, as well as for validation of highresolution climate and regional models.

\section{Introduction}

The poleward flow of the Atlantic Water (AW) through the Nordic Seas represents the key component of the meridional overturning circulation (Spall, 2010; Lozier et al., 2019; Chafik \& Rossby, 2019). AW is subjected to important heat losses, convection, and densification on its way to the Arctic (Rossby et al., 2009b; Bosse et al., 2018). It enters the Nordic Seas with the Norwegian Atlantic Current through the straits between Iceland, Faroe Islands, and Shetland Islands. The Norwegian Atlantic Current is constituted by two main branches: the Norwegian Atlantic Front Current (NwAFC) and the Norwegian Atlantic Slope Current (NwASC) which bound the Lofoten Basin (LB) from the eastern and the western sides respectively (Fig.1). The NwASC is about two times stronger than the NwAFC along 
the Svinøy section at 63N (e.g. Mork \& Skagseth, 2010). Both branches have a prominent seasonal cycle that has been linked to wind forcing (Jakobsen et al., 2003; Mork \& Skagseth, 2010; Skagseth et al., 2015; Bosse \& Fer, 2019a). Gascard and Mork (2008) used Lagrangian observations from ARGO and RAFOS floats and describe NwASC at the depth of 300-1000 $\mathrm{m}$ as "a turbulent, broad $(100 \mathrm{~km})$ and slow current $\left(\sim 6 \mathrm{~cm} \mathrm{~s}^{-1}\right.$ mean velocity) progressing to the north".

The LB is a $3300 \mathrm{~m}$ deep topographic depression bounded by the Vøring Plateau in the south, the Mohn's Ridge in the west and the Eurasian continental shelf in the east. It is one of the most energetic regions regarding eddy kinetic energy in the Nordic Seas (Poulain et al., 1996), characterized by the presence of local maxima of sea surface height (SSH) and strong flow variability.

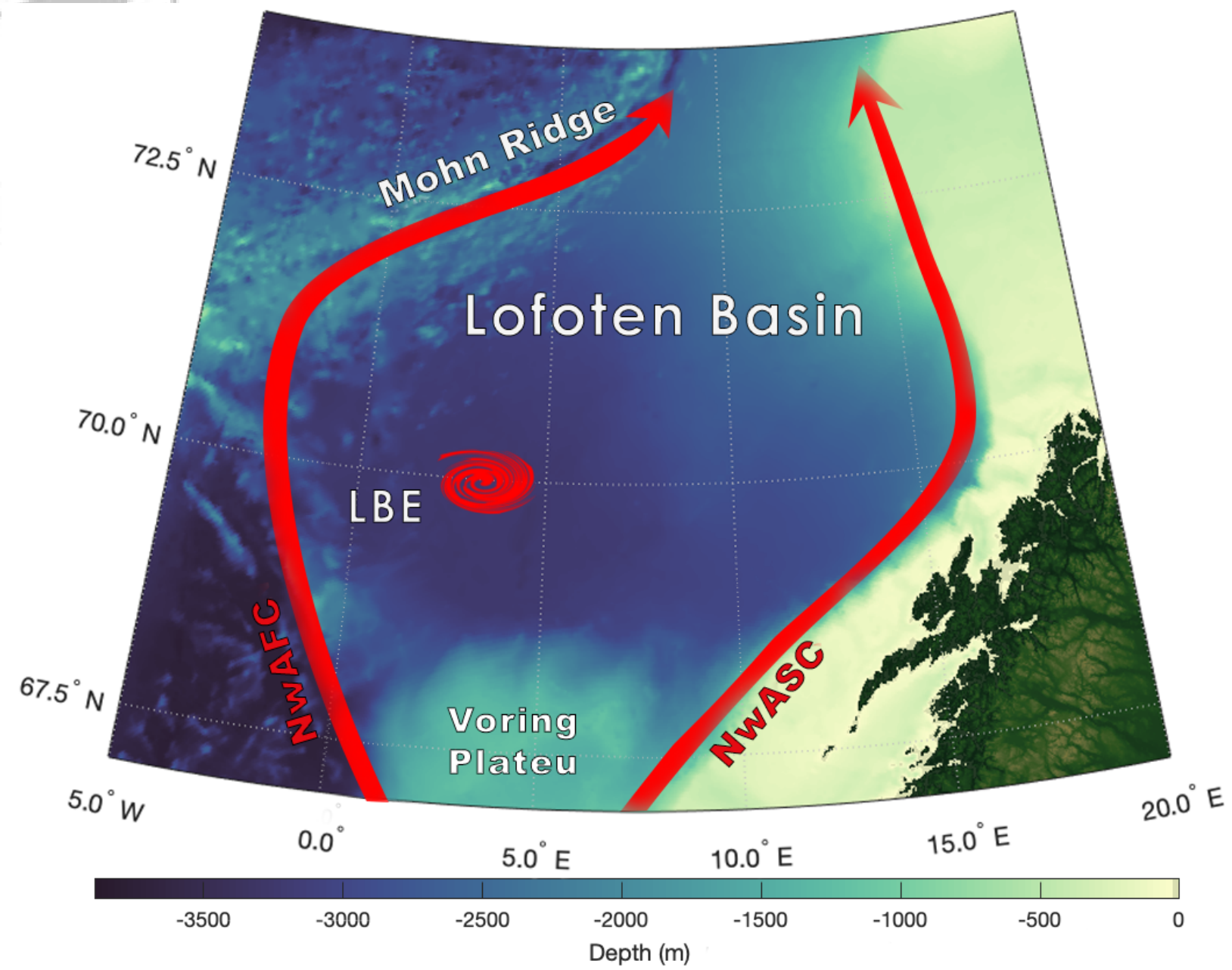

Figure 1. The Lofoten Basin region with the bathymetry (Amante \& Eakins, 2009) and schematic path of the Norwegian Atlantic Slope Current (NwASC) and the Norwegian Atlantic Front Current (NwAFC). The red spiral indicates the area where the Lofoten Vortex (LV) is generally observed. 
A large-scale barotropic cyclonic circulation is formed in the LB due to the conservation of potential vorticity (Belonenko et al., 2014; Voet et al., 2010). Volkov et al. (2013) detected a time-averaged cyclonic wavelike propagation of the mesoscale sea level anomalies around the center of the LB. They identified dipole and quadrupole wavelike modes of propagation and demonstrated that these modes are responsible for the observed amplification of SSH variability in the center of the LB. Moreover, the cyclonic circulation in deep layers keeps a large amount of AW inside the LB area and significantly increases its residence time in the basin (Fig. 2).

Mesoscale eddies trap water and transport momentum, volume, heat, salt and biogeochemical constituents from their generation regions to dissipation sites (Chelton et. al., 2011a). One of the key features of the mesoscale dynamics in the LB is the generation of eddies from the NwASC by baroclinic instability and their westward propagation which results in heat and salt transport to the central part of the basin (Köhl, 2007; Rossby et al., 2009a; Spall, 2010; Andersson et al., 2011; Volkov et al., 2015). The shedding of eddies also contributes to the gradual cooling of NwASC on its way to the Arctic Ocean. Such heat loss, in turn, may have a significant influence on the sea ice cover in the Barents Sea (Isachsen et al., 2012; Sandø et al., 2010; Årthun et al., 2012). In addition, mesoscale eddies transport nutrients and modulate biological activity by providing local rich feeding habitat for the biota (Falkowski et al., 1991; Gaube et al., 2013). Therefore, a detailed study of mesoscale eddies in the LB is crucial to the understanding of dynamic, climatic and biological processes in the region. 


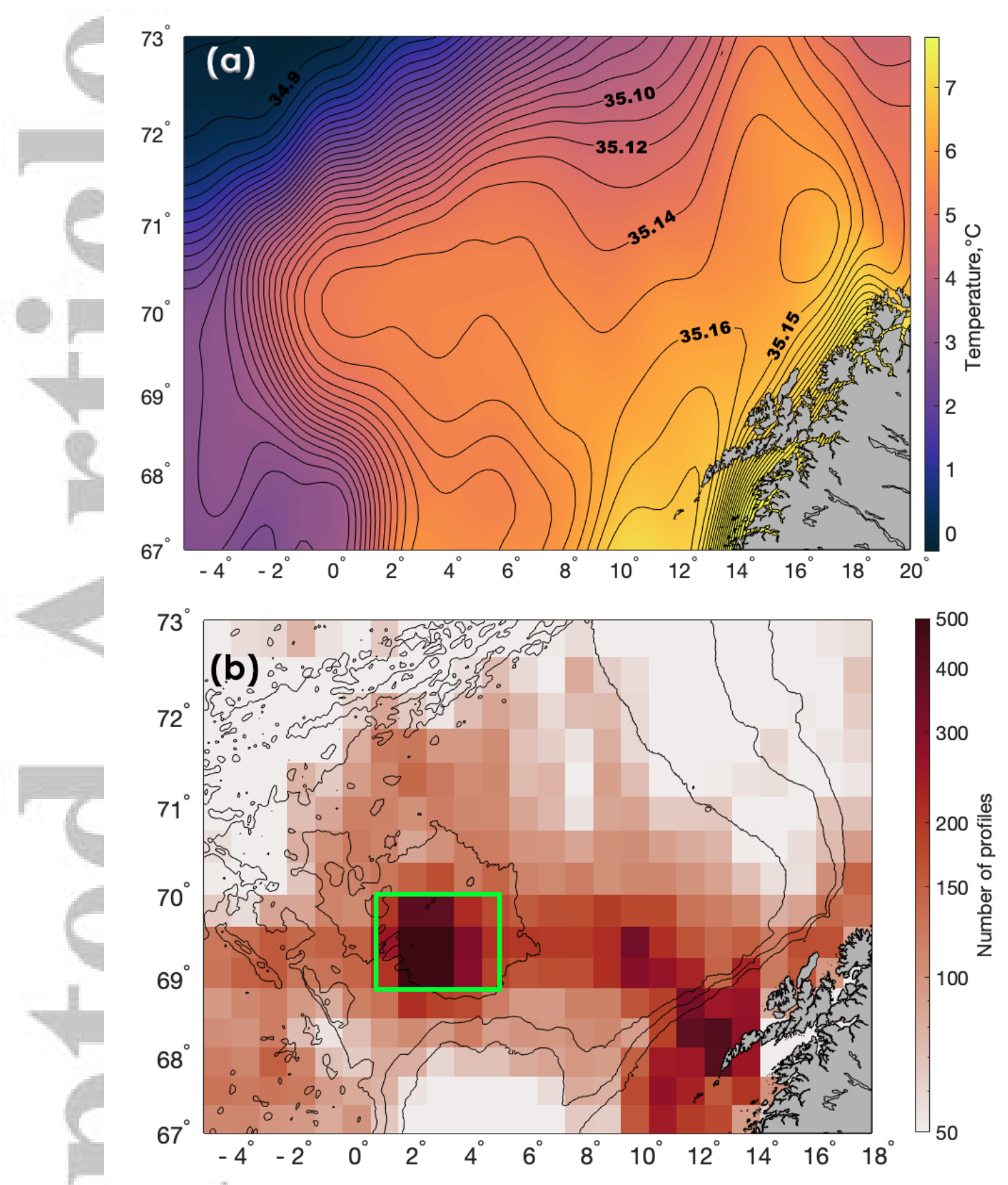

Figure. 2. (a) Objective maps of temperature (color shading) and salinity (contours) climatology at the $300 \mathrm{~m}$ depth calculated from the data set "Hydrography of the Nordic Seas, 2000-2017: A merged product" (Bosse \& Fer 2018). (b) Spatial distribution of the available hydrographic profiles in the Lofoten Basin (the number profiles in $1^{\circ} \times 0.35^{\circ}$ bin for the period 2000-2017). The green box indicates the area where the Lofoten Vortex (LV) is generally observed.

Mesoscale features of the LB have previously been investigated in a number of studies based on surface and subsurface drifters (e.g. Poulain et al., 1996; Jakobsen et al., 2003; Gascard \& Mork, 2008; Søiland et al., 2008; Rossby et al., 2009a, 2009b; Voet et al., 2010; Koszalka et al., 2011), numerical modeling (e.g. Köhl, 2007; Spall, 2010; Bashmachnikov et al., 2018; 
Zinchenko et al., 2019), altimetry (e.g. Volkov et al., 2013, 2015; Raj et al., 2016; Raj \& Halo, 2016) and in situ observations (e.g. Soiland et al., 2013, 2016; Yu et al., 201; Belonenko et al., 2018; Bosse et al., 2019). The majority of these studies focused on the quasi-permanent anticyclonic Lofoten Vortex (LV) located in the deepest part of the LB. Russian oceanographers were the first to describe the LV as a long-lived circulation feature (Alexeev et al., 1991; Ivanov \& Korablev, 1995a, 1995b). LV represents a lens of warm and saline AW in the layer of 300-1000 m depth with a horizontal scale of $100 \mathrm{~km}$. The LV translates in a cyclonic motion relative to the center of the basin at a speed of $3-4 \mathrm{~cm} / \mathrm{s}$ (Søiland et al., 2013; Bosse et al., 2019). Intense maximum orbital velocities in the vortex reach 50-70 cm/s (Yu et al., 2017; Bosse et al., 2019; Zinchenko et al., 2019; Travkin \& Belonenko, 2019). There is still no unified opinion about the mechanisms responsible for its exceptional stability. It is clear that deep convection in winter is a necessary condition for the existence of the LV since it creates favorable conditions for its annual regeneration (Bloshkina \& Ivanov, 2016; Fedorov et al., 2019; Bosse et al., 2019). In recent years a number of studies also suggested that a primary source of energy sustaining LV could be provided by anticyclones shed from the NwASC and propagating into the central basin (Köhl, 2007; Rossby et. al., 2009; Søiland \& Rossby, 2013; Zinchenko et al., 2019; Travkin \& Belonenko, 2019; Bosse et al., 2019).

Raj et al. (2016) presented a comprehensive observation-based quantitative analysis of mesoscale eddies in the Lofoten Basin using a combination of gridded altimeter, Argo floats and surface drifter data. As a result, the authors documented the horizontal structure and kinematic properties of LB eddies, without excluding the LV from their analysis. However, the vertical thermohaline structure of the mesoscale eddies and their contribution to the heat and salt transports in the LB region remains unexplored.

The main objective of this work is to assess the vertical thermohaline structure of LB eddies (excluding the LV) and their impact on water masses and transports in the LB. We here focus on the general mesoscale activity of the LB, excluding from our study the quasi-permanent anticyclonic LV which has already been thoroughly analyzed (see references hereinabove). Moreover, the vertical extension of the LV core can reach the depth of $1200 \mathrm{~m}$ (Yu et al., 2017; Søiland et al., 2016) which significantly exceeds the average lower boundary of the core for the mesoscale eddies in the study region. To achieve our goal, we apply the method of colocalization of altimetry data and CTD profiles from multiple platforms (research vessels, autonomous profiling floats, and gliders), which allow us to obtain composite structures of cyclonic (CE) and anticyclonic (AE) eddies. The spatial distribution of thermohaline 
characteristics of mesoscale eddies in the basin could be used to estimate the heat and salt transported by these vortices at the basin-scale.

The paper is organized as follows: section 2 provides details about the data and methods used in this study; section 3 focuses on the obtained radial and three-dimensional structures of the composite $\mathrm{AE}$ and $\mathrm{CE}$, as well as eddy-induced heat and salt transports. Summary and conclusion are formulated in the section 4.

\section{Data and Methods}

Assessment of the spatial thermohaline structure of mesoscale eddies is a challenging task. The main problem is the difficulty of obtaining a sufficient number of hydrological profiles within the borders of single eddy. However, thanks to the development of the ARGO program, currently including almost 4000 profiling floats worldwide (Argo, 2020), and the development of automatic eddy identification algorithms to identify and track mesoscale eddies in SLA fields, a new methodology of colocalization the altimetry and in situ data has recently been developed. The method was presented in Willis and Fu (2008) and Chaigneau et al. (2011) and has been extensively used in a number of studies covering different regions of the World Ocean (e.g. Yang et al., 2013; Dong et al., 2017; He et al., 2018; Yu et al., 2017; Kubryakov et al., 2018; Keppler et al., 2018).

\subsection{Mesoscale Eddy Trajectory Atlas Product}

To identify the position of mesoscale eddies and track their propagation, we used the "Mesoscale Eddy Trajectory Atlas Product" based on the algorithm developed by Chelton et. al. (2011a) and applied to sea level anomaly (SLA) from merged multimission satellite measurements. The algorithm was modified as described in Schlax and Chelton (2016) based on the approach described by Williams et al. (2011). The "growing" method of eddy identification defines the anticyclonic eddy interior by finding a local maximum in SSH and all neighboring pixels whose SSH values lie above a sequence of decreasing thresholds. This "growth" of the eddy interior is continued until some criteria for this coherent structure are violated. Cyclonic eddies are defined in the same way by finding the local minimum of SSH (Schlax $\&$ Chelton, 2016).

The position of each eddy center is defined as the SSH-based eddy centroid formed by the outermost closed contour of SSH. The coordinates of the centroid $\left(x_{c}, y_{c}\right)$ are defined to be 


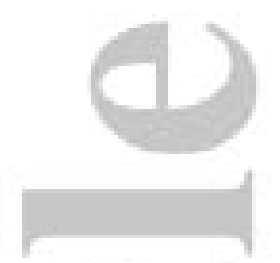

$$
\begin{aligned}
& x_{c}=\frac{\sum_{(i, j) \in E} x(i) h(i, j)}{\sum_{(i, j) \in E} h(i, j)}, \\
& y_{c}=\frac{\sum_{(i, j) \in E} y(i) h(i, j)}{\sum_{(i, j) \in E} h(i, j)}
\end{aligned}
$$

Here $x(i)$ is the longitude (the $i$ index) and $y(j)$ is the latitude (the $j$ index) of the pixels with its specified SSH value defined as $h(i, j)$, and the point $(i, j) \in E$, where $E$ is the connected set of pixels defining the eddy (Schlax \& Chelton, 2016).

The minimal size of the detected eddies is limited by the spatial resolution of the gridded SLA fields. Chelton et al. (2011b) demonstrated that the filtering in the objective analysis procedure used to construct the gridded SLA fields has a half-power cutoff of about $2^{\circ}$ which corresponds to a Gaussian e-folding radius of $\sim 0.4^{\circ}$. In the Lofoten Basin, it means that eddies with zonal scales less than about $15 \mathrm{~km}$ cannot be detected. The minimum and maximum radius from the Mesoscale Eddy Trajectory Atlas Product for the eddies detected in the Lofoten basin are $14 \mathrm{~km}$ and $145 \mathrm{~km}$ respectively. The mean radius of the AEs and CEs in the Lofoten Basin are $55.2 \pm 19.4 \mathrm{~km}$ and $55.0 \pm 19.2 \mathrm{~km}$ respectively. The obtained estimates are consistent with the known distribution of the eddy sizes in the LB region (e.g. Raj et. al., 2016; Zinchenko et al. 2019; Gordeeva et. al., 2020). For more details about the algorithm please refer to Williams et al. (2011) and Schlax and Chelton (2016).

The dataset is now routinely generated and quality-controlled by the Data Unification and Altimeter Combination System (DUACS) and distributed by AVISO+. We use version 2.0 of the dataset delivered in September 2018 with the new input data and improved eddy identification and tracking procedure. The dataset and the documentation with a detailed description of the modified algorithm are available at https://www.aviso.altimetry.fr. The final version of the dataset contains the location of detected eddies on each day for the whole altimetry period (1993-ongoing), polarity (cyclonic/anticyclonic), rotational speed, amplitude, radius (scale) and associated metadata.

\subsection{Hydrographical data set}

In order to construct the three-dimensional composite structure of eddies, we used vertical temperature and salinity profiles acquired from the data set "Hydrography of the Nordic Seas, 2000-2017: A merged product" (Bosse \& Fer 2018). The dataset is freely available at https://doi.org/10.21335/NMDC-1131411242. This merged data set contains hydrographical observations from different sources for the 2000-2017 period, between $61-80 \mathrm{~N}$ and $17 \mathrm{~W}-23 \mathrm{E}$. Shipborne CTD profiles were downloaded from the ICES database and 
combined with Norwegian Marine Data Center for the Svinøy, Gimsøy, Barents Sea Opening, and Bear Island sections, as well as dedicated cruises in the Lofoten Basin (Fer et al., 2019). Profiles collected by Argo profiling floats were retrieved from the Coriolis data center (Argo, 2020). Finally, 10 glider missions carried out in the Lofoten Basin by the University of Bergen under NACO (North Atlantic Current Observatory) and PROVOLO (Water mass transformation processes and vortex dynamics in the Lofoten Basin of the Norwegian Sea) projects were added to the dataset (Fer \& Bosse, 2017; Bosse \& Fer, 2019b). Prior to merging, the data from different sources were consistently interpolated on a $5 \mathrm{db}$ pressure grid from 0 to $3000 \mathrm{db}$. Duplicates from various sources were removed and a merging of profiles at mesoscale was used to homogenize the sampling rate of the different platforms. Out of 77,625 initial profiles, the final merged data set contains 57,753 state-binned profiles. Details on the data processing can be found in Bosse et. al. (2018).

Figure 2 shows the objective maps of the annual mean climatology of temperature and salinity at $300 \mathrm{~m}$ depth derived from this data set. The objective maps demonstrate that the warmest and saltiest waters are observed in the eastern and southeastern parts of the study area along the Norwegian shelf where the mean conservative temperature exceeds $8^{\circ} \mathrm{C}$ and absolute salinity reaches $35.2 \mathrm{~g} / \mathrm{kg}$. At the scale of the $\mathrm{LB}$, a temperature and salinity gradient can be observed in the southeast/northwest direction.

Figure $2 \mathrm{~b}$ demonstrates a spatial distribution of the CTD profiles acquired from the hydrographical data set for the LB region. The maximum number of CTD casts were carried out in the LV area. The high density of profiles in the LV area is not surprising as the quasipermanent anticyclonic vortex in the LB represents a natural laboratory for studying vortex dynamics in the ocean and has been the focus of extensive dedicated surveys over the years by research vessels and more recently by autonomous gliders (Yu et al., 2017; Bosse et al., 2019). Since the aim of our work is mesoscale eddies of the LB region (except the quasi-permanent Lofoten vortex), we exclude LV area from the initial data sets. The general area of LV defined as $1^{\circ}-5^{\circ} \mathrm{E}, 69^{\circ}-71^{\circ} \mathrm{N}$ (Soiland \& Rossby, 2013; Belonenko et al., 2014, 2018; Raj et al., 2015; Yu et. al., 2017; Bosse et al., 2019).

Figure $2 \mathrm{~b}$ shows that the whole study area is well covered with observations. More than $50 \%$ of $30 \times 30 \mathrm{~km}$ bins contain $200-300$ profiles and less than $5 \%$ of bins have less than 50 profiles, therefore we can conclude that the LB region is well covered with CTD profiles. The total number of the profiles for the LB region is 17,985 without including the LV area $(18,905$ with the LV area) which corresponds to the $\sim 31 \%$ of the initial data set. 


\subsection{Colocalization method}

Each selected profile was associated with the nearest eddy if it satisfied the two following conditions: (1) The profile and the eddy have the same observation day; (2) The profile is located within a distance less than the eddy radius $\mathrm{R}$ derived from the "Mesoscale Eddy Trajectory Atlas Product". Figure 3a displays the geographical distribution of the acquired profiles in the study area. The distance between the location of the profile and the eddy center was normalized by the radius R. Normalized distance 0 corresponds to the eddy center while normalized distance 1 corresponds to the eddy maximum velocity average within the contour defining the eddy. The satellite-derived eddy radius $\mathrm{R}$ is equivalent to a dynamical radius characterized by zero vorticity $\left(\mathrm{R}=\sqrt{2} \mathrm{R} \_\mathrm{m}\right.$ for Gaussian eddies with $\mathrm{R} \_\mathrm{m}$ the radius defined by maximum orbital velocity). This approach is based on the assumption made by Zhang et al. (2013) that mesoscale eddies, regardless of their amplitude, polarity or scale have the same structure, therefore the radial distribution of the eddy's thermohaline structure can be considered as universal. Subsequent works that followed that technique confirmed the feasibility of this approach (e.g. He et al., 2018; Kubryakov et al., 2018; Keppler et al., 2018). However, we increase the size of the composite eddy to $1.5 \mathrm{R}$ (equivalent to about $2.1 \mathrm{R} \_\mathrm{m}$ ), as the presence of eddies also influences its vicinity. Mesoscale eddies often have elongated shapes since they are prevalent in the areas where dynamic effect of the background currents is dominant. As a result, eddies experience a significant influence from the background flows at distances that can exceed its radius. When the vortex interacts with external currents, initial perturbations are formed at the vortex boundary. These disturbances can grow and simultaneously expand due to the current shear. Such influence can be tracked within distance of 1.5 and even 2R_m (He et al., 2018).

Analyzed profiles were classified into two groups depending on the vorticity sign: AE and $\mathrm{CE}$. The number of profiles located within the distance less than $\mathrm{R}$ away from center of $\mathrm{AE}$ and $\mathrm{CE}$ is 703 and 456, respectively. The total number of profiles located within the distance of $1.5 \mathrm{R}$ from the eddy center is 1504 for $\mathrm{AE}$ and 1131 for CE. Their position relative to the eddy center is given in the fig. $3 b$ and $3 c$. The total number of unique eddies with the detected profiles within the distance of $1.5 \mathrm{R}$ from the eddy center is 292 AEs and 258 CEs.

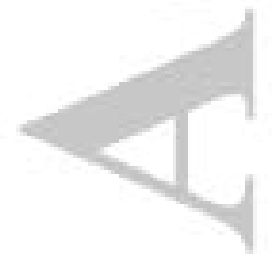



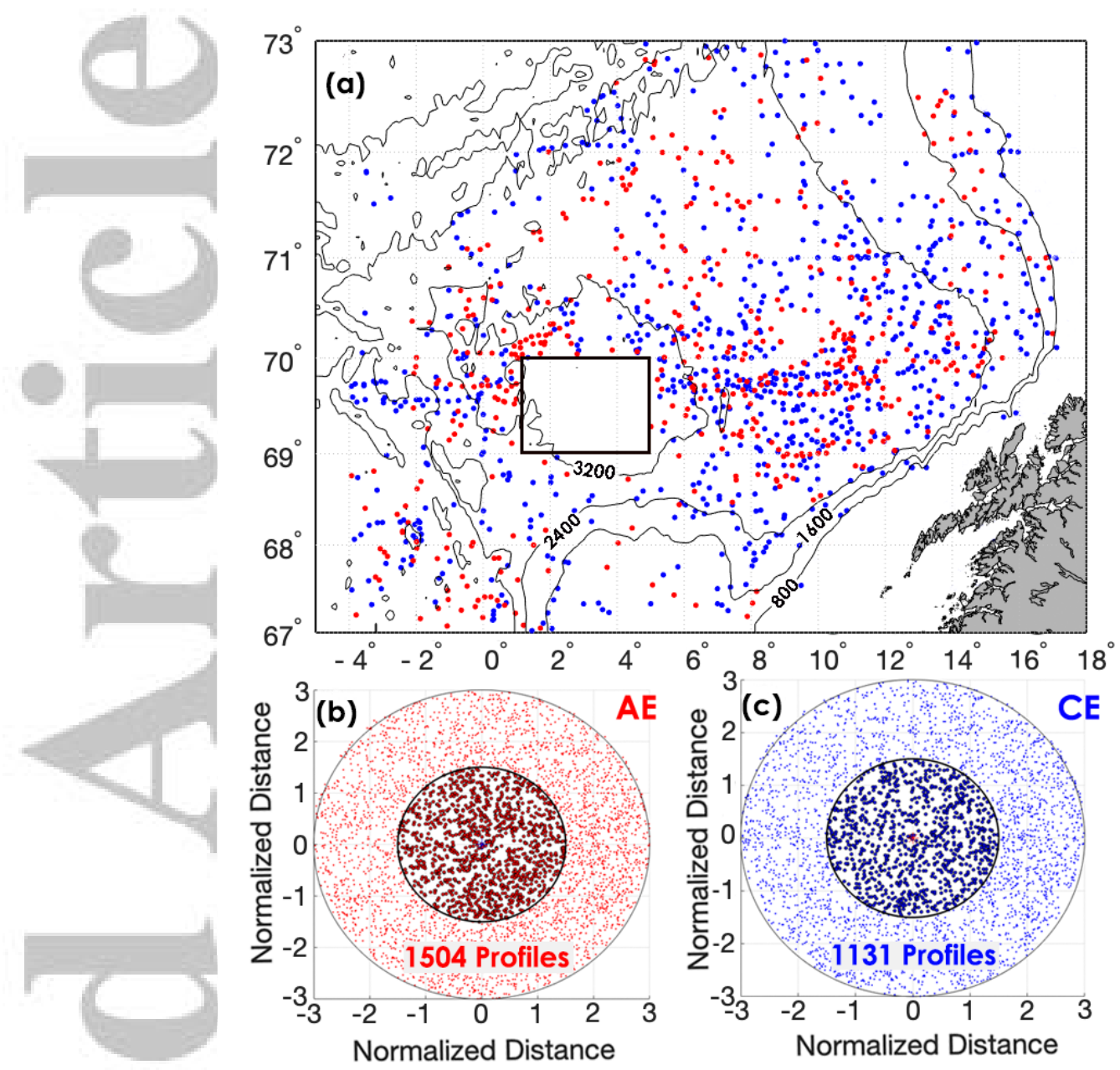

Figure 3. (a) Geographical position of the hydrographical profiles acquired inside anticyclonic (red dots) and cyclonic (blue dots) eddies for the period 2000-2017 in the LB region and bathymetric contours; $(b, c)$ The distribution of the obtained profiles in the normalized eddycoordinate system associated with anticyclonic and cyclonic eddies.

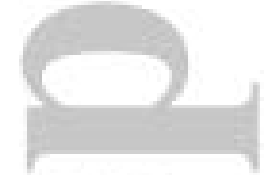

In order to better understand the vertical thermohaline structure of the mesoscale eddies and estimate zonal transport induced by CEs and AEs, the temperature $\left(T^{\prime}\right)$ and salinity $\left(S^{\prime}\right)$ anomalies were calculated by subtracting monthly local mean climatological $T / S$ profiles from $T / S$ profiles associated with the eddies. The mean climatology was computed from the hydrographical data set within $2.5 \mathrm{R}$ around each eddy observation. To construct threedimensional composite eddy structure retained $T^{\prime} / S^{\prime}$ profiles were finally interpolated onto a regular $0.1 \times 0.1 \mathrm{R}$ grid at each depth level $(5 \mathrm{db})$ using Barnes objective analysis with the smoothing length scale of 0.5 for both radial and vertical axis (Barnes, 1973; Keppler et al., 2018). 
Additional quality criteria were applied to the selected hydrographic profiles. Profiles with the first record below $20 \mathrm{~m}$ and less than 10 unique records were removed (Chaigneau et al., 2011). Moreover, profiles with values greater than three standard deviations from the monthly climatology were considered as outliers and eliminated as well. Eddy profiles in areas shallower than $500 \mathrm{~m}$ were also discarded.

Another question can arise due to the noise of the sampling. All profiles come from different eddies with various shapes and asymmetry. We obtain 3D composite structures by averaging a significant number of profiles. This procedure eventually reduces the statistical noise of the composite structures. As pointed out in previous studies (e.g., Willis \& Fu, 2008; Chaigneau et. al., 2011; Keppler et. al., 2018) the method of in situ measurements colocalization with eddies in time and space is subjected to potential errors associated with positioning precision of hydrographic profiles and eddy centers detection. The position of eddy centroid is calculated by analyzing daily interpolated SLA maps which have certain limitations and mapping errors due to the spatio-temporal gaps in altimetry tracks sampling. See Chelton et al. (2011a) for detailed information on the AVISO data processing and implemented solutions for reducing the errors. Since the data set we use contains merged profiles from the different sources, the positioning error can vary depending on different types of profiles. For their study region, Chaigneau et al. (2011) estimated the average total error of positioning Argo floats of $\sim 1 \mathrm{~km}$, while under certain extreme conditions it can reach $\sim 5 \mathrm{~km}$. It should be noted, that estimated positioning error is considerably lower of an average radius of the mesoscale eddies in the LB. Despite certain shortcomings of the method, the large number of profiles increase the statistical significance of the signals associated with the eddies. Following the approach of Chaigneau et al. (2011) we performed the non-parametric Mann-Whitney U-test $(\mathrm{p}<0.05)$ which justifies the statistical significance of obtained profiles. The test confirms that the $T^{\prime} / S^{\prime}$ anomalies computed inside eddies are significantly different from the $T^{\prime} / S^{\prime}$ anomalies outside eddies.

Following Chagneau et al. (2011), we estimated the eddy-induced volume, heat and salt anomalies transported by AEs and CEs and their contribution to the heat and salt fluxes in the LB region. To estimate the spatial distribution of zonal and meridional eddy induced transport we follow the approach of Dong et al. (2017), who proposed a new method using eddy trajectories instead of propagation velocity (e.g. Dong et al., 2014).

Taking into account the spatial resolution of SLA gridded data and difference in size between latitude and longitude for the study region, we divide LB area into $1^{\circ} \times 0.35^{\circ}$ grid cells (about $40 \mathrm{~km}$ squares at $69.5 \mathrm{~N}$ ). For every cell, we tracked the number of eddies crossing the cell 
boundaries (i.e., western/eastern boundary for zonal transport and northern/southern boundary for meridional transport).

Transport $(D)$ is calculated as $D=\frac{V N}{M}$, where $V$ is the volume of water transported by a single composite eddy, $N$ is the number of detected eddies that crossed the cell boundary and $M$ is the time of the analysis period. Westward and northward transports are defined as positive. For every cell the zonal (resp., meridional) volume transport was calculated as an average between transports of the western and eastern (resp., northern and southern) borders of the cell.

\section{Results}

\subsection{Radial Structures}

In order to analyze and compare the vertical thermohaline structure of AEs and CEs in the LB region, we made radial composite sections of temperature, salinity and density anomalies (Figure 4). Significant eddy-induced $\mathrm{T}^{\prime} / \mathrm{S}^{\prime}$ anomalies $\left(>0.1^{\circ}\right.$ and $>0.01 \mathrm{~g} / \mathrm{kg}$ for AE and $<0.1^{\circ}$ and $<0.01 \mathrm{~g} / \mathrm{kg}$ for CE, corresponding to about $10 \%$ of the maximum $\mathrm{T}^{\prime} / \mathrm{S}^{\prime}$ associated with eddies) are concentrated within one radius $\mathrm{R}$ and the depth of about $900 \mathrm{~m}$, associated with the displacement of the AW pycnocline. We also note that the composite eddies of both polarities significantly influence the thermohaline characteristics at the horizontal distance up to at least $1.5 \mathrm{R}$.

The positive temperature anomaly in the composite AE is concentrated within the depth range of 150-900 $\mathrm{m}$. The eddy core is located in the layer of 550-700 m with a maximum of about $+1.0^{\circ} \mathrm{C}$ at $600 \mathrm{~m}$ (Figure $4 \mathrm{a}$ ). The distribution of the salinity anomaly in the composite $\mathrm{AE}$ shows a similar pattern with a maximum of $+0.05 \mathrm{~g} / \mathrm{kg}$ at around $600 \mathrm{~m}$ (Figure $4 \mathrm{~b}$ ). The radial section of density anomalies for the composite $\mathrm{AE}$ mostly follows the temperature anomaly distribution with a minimum at $\sim 600 \mathrm{~m}$, density being mostly controlled by temperature in this region. Using the Thermodynamic Equation of Seawater (TEOS-10) we estimated that the temperature anomalies contribute more than $90 \%$ to the density anomaly of eddies of both polarities. 

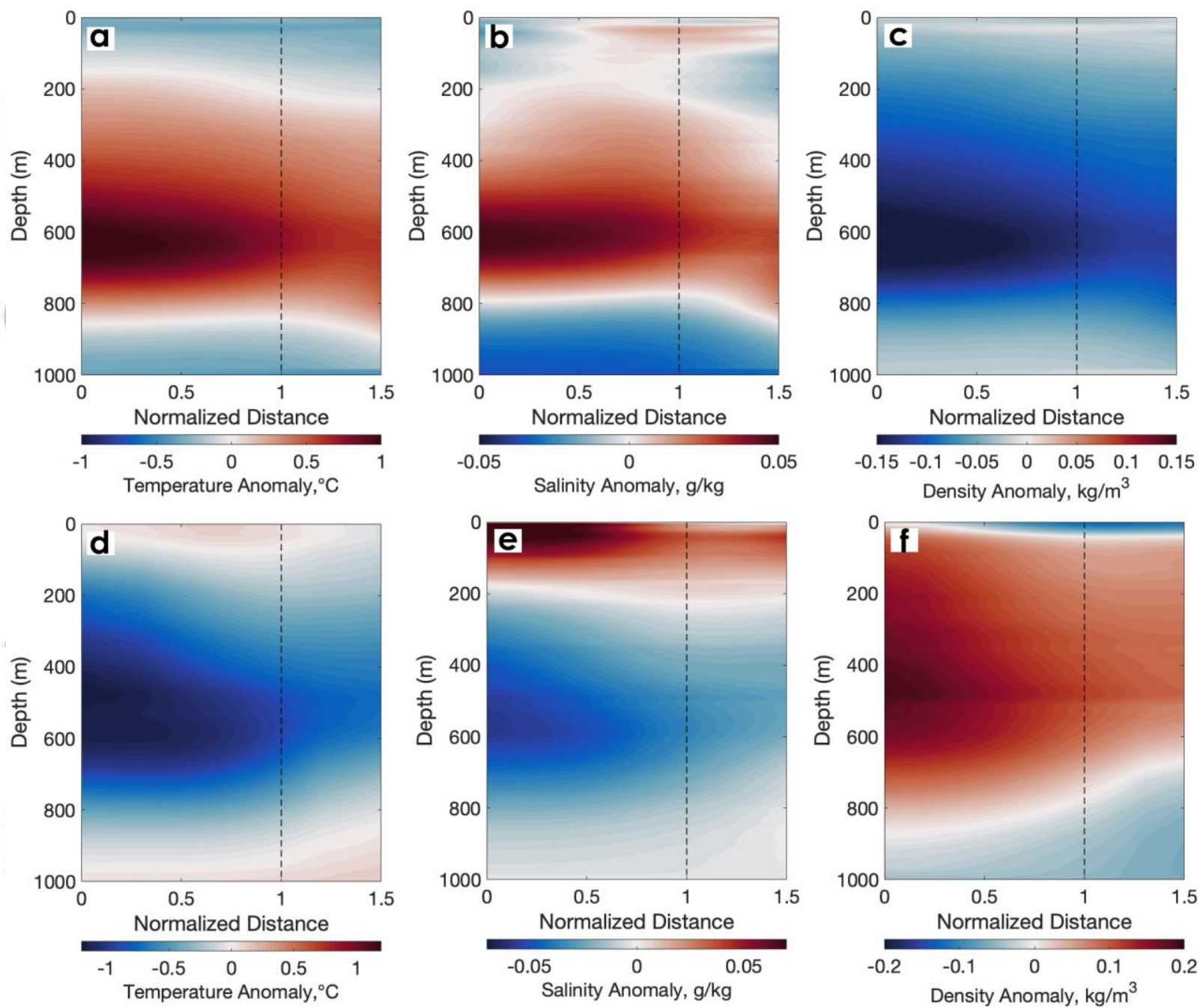

Figure 4. Radial cross-sections of temperature (a,d), salinity (b,e) and density (c,f) anomalies in the composite anticyclonic (top) and cyclonic (bottom) eddies.

The thermohaline structure of the composite CE shows a similar pattern yet with negative anomalies for temperature and salinity, and positive for density. The core of the composite CE is located within the $300-600 \mathrm{~m}$ layer with a negative peak at the $500 \mathrm{~m}$. The minimum temperature anomaly equals $-1.26{ }^{\circ} \mathrm{C}$ (Fig. $4 \mathrm{~d}$ ) and the minimum value of salinity anomaly is $-0.06 \mathrm{~g} / \mathrm{kg}$ (Fig. 4e). However, in comparison with the composite AE, the composite CE has a "dipole-like" structure in the salinity distribution (Fig. 4e). The positive anomaly of salinity is concentrated in the upper layer from the surface to $200 \mathrm{~m}$ with a maximum value of $0.07 \mathrm{~g} / \mathrm{kg}$. It can be explained by the deflection of isohaline in CEs. However, a similar structure is hardly noticeable in the temperature and density radial cross-sections. Such "dipole-like" structures manifest themselves in the composite salinity distribution, but with insignificant influence on density (values of density in the upper layer are close to zero, see Fig. 4f). 


\subsection{Three-Dimensional Structures of the Composite Eddies}

Figures 5 and 6 show the three-dimensional structure of the AE and CE composites in the $\mathrm{LB}$ respectively and horizontal distributions of the temperature and salinity anomalies $\left(\mathrm{T}^{\prime}\right.$, $\left.\mathrm{S}^{\prime}\right)$ at selected depth levels.

The core of the composite AE has a gradual increase of $\mathrm{T}^{\prime}$ and $\mathrm{S}^{\prime}$ anomaly with depth (Fig. 5): from $0.4{ }^{\circ} \mathrm{C}$ and $0.03 \mathrm{~g} / \mathrm{kg}$ at $200 \mathrm{~m}$ to $0.9^{\circ} \mathrm{C}$ and $0.05 \mathrm{~g} / \mathrm{kg}$ at $600 \mathrm{~m}$. The maximum $\mathrm{T}^{\prime}$ and $\mathrm{S}^{\prime}$ in the composite $\mathrm{AE}$ is $1.0^{\circ} \mathrm{C}$ and $0.07 \mathrm{~g} / \mathrm{kg}$ at $650 \mathrm{~m}$ and about zero anomaly near the surface and at around $1000 \mathrm{~m}$. The temperature anomalies $>0.1^{\circ} \mathrm{C}$ are detectable down to depths of $\sim 950 \mathrm{~m}$ in the composite AE. From the depth of $600 \mathrm{~m}$, the eddy signature gradually decreases with depth in both salinity and temperature. Figure 6 demonstrates 3D distributions of temperature and salinity anomalies for the composite CE. The minimum $\mathrm{T}^{\prime}$ and $\mathrm{S}^{\prime}$ in the composite $\mathrm{CE}$ is $-1.6^{\circ} \mathrm{C}$ and $0.30 \mathrm{~g} / \mathrm{kg}$ at $500 \mathrm{~m}$ and maximum $\mathrm{T}^{\prime}$ and $\mathrm{S}^{\prime}$ is $0.62^{\circ} \mathrm{C}$ and 0.013 $\mathrm{g} / \mathrm{kg}$ in the surface layer.

Despite significant differences, both composite eddies have some common features. Note that the composite $\mathrm{AE}$ and $\mathrm{CE}$ both have an asymmetric spatial distribution of $\mathrm{T}^{\prime} / \mathrm{S}^{\prime}$ with extrema (maximum for $\mathrm{AE}$ and minimum for $\mathrm{CE}$ ) shifted at $\sim 0.5 \mathrm{R}$ relative to the eddy axis in the southeast direction (Fig. 5 and 6). In other words, AEs in the LB are warmer and saltier in the southwest than the northeast side, similarly, CEs are colder and less salty in their southeast side. It might be a specific feature of mesoscale eddies in the LB region due to the east/west temperature and salinity gradients at the basin-scale.

The asymmetry of temperature and salinity in eddies is characteristic of mesoscale eddies in many ocean basins due to the non-linear eddy dynamic (Pegliasco et al., 2015; He et al., 2018; Ma et al., 2015; Simons et al., 2015). Mesoscale eddies have a strong influence on the hydrological field during their propagation. Generated by the instability of currents, they trap and keep thermohaline and biogeochemical properties of their parent flow and redistribute them throughout their pathway. Non-linear eddies trap fluid inside their core, therefore it might be surprising that the extrema in $\mathrm{T}^{\prime} / \mathrm{S}^{\prime}$ distributions are not exactly found at the geometric eddy centers. However, the asymmetry in the eddies was found as an ubiquitous feature (Chelton et al., 2011b; Kubryakov et al., 2016). Yuan and Castelao (2017) analyzing eddy-induced sea surface temperature gradients in Eastern Boundary Current Systems indicated that temperature anomalies in the eddies are subjected to many processes, including upwelling, flow instabilities, flow-topography interactions, and mesoscale variability. Temperature and salinity in eddies are closely related to underlying ocean submesoscale processes. As the background 
fields of temperature and salinity have a strong east-west gradient in the Lofoten Basin (see Fig. 2), we can expect that the extrema of eddy-induced $\mathrm{T}^{\prime} / \mathrm{S}^{\prime}$ would be shifted in roughly the same direction.

Figure 7 shows the mean vertical profiles of temperature, salinity and density anomalies obtained by averaging all profiles associated with AEs and CEs and located within the distance of $0.5 \mathrm{R}$ from the eddy center. The mean $\mathrm{AE}$ and $\mathrm{CE}$ signature is mostly symmetric and of opposite sign in terms of temperature and salinity anomalies (positive for AEs and negative for CEs). The temperature anomalies larger than $0.1{ }^{\circ} \mathrm{C}$ for the $\mathrm{AE}$ (resp., smaller than $-0.1^{\circ} \mathrm{C}$ for the $\mathrm{CE}$ ) are detectable above $900 \mathrm{~m}$ depth (Fig. 7a). Again, we can see the distinct characteristics in the morphology previously observed in the radial sections: the largest temperature anomalies for the $\mathrm{AE}$ with typical values approximately $0.9^{\circ} \mathrm{C}$ at $\sim 650 \mathrm{~m}$, while for the $\mathrm{CE}$ the strongest temperature anomalies $\left(<-1^{\circ} \mathrm{C}\right)$ are found at $\sim 500 \mathrm{~m}(\mathrm{Fig} .4-6)$. The salinity anomalies for CEs have a positive sign in the upper $200 \mathrm{~m}$ weakening with depth, changing sign at $\sim 200 \mathrm{~m}$ and reaching minimum at $\sim 600 \mathrm{~m}(-0.04 \mathrm{~g} / \mathrm{kg})$. A double structure with a core of more saline water in the upper layer and of fresher water deeper than $200 \mathrm{~m}$ is hence observed (Fig. 7b). The largest mean salinity anomalies in the composite AE are found at $\sim 600 \mathrm{~m}$ depth $(0.05 \mathrm{~g} / \mathrm{kg})$. The mean salinity anomalies for both composite AE and CE are close to zero at $1000 \mathrm{~m}$ depth. The vertically averaged temperature and salinity anomalies are $0.52^{\circ} \mathrm{C}$ and $0.02 \mathrm{~g} / \mathrm{kg}$ for the $\mathrm{AE}$ and $-0.62{ }^{\circ} \mathrm{C}$ and $-0.01 \mathrm{~g} / \mathrm{kg}$ for the $\mathrm{CE}$. The profiles of mean potential density anomalies are mostly consistent with temperature anomalies (Fig. 7c) for both $\mathrm{AE}$ and $\mathrm{CE}$ which again demonstrates that $\mathrm{CEs}$ density anomalies are mostly driven by temperature anomalies. However, the upper layer of $\mathrm{CE}$ is characterized by a positive density anomaly driven by salinity. A possible explanation for the different salinity anomalies near the surface of the AE and CE could be related to outcropping isopycnals near the CEs. These would create a frontal region that, unlike for the AEs that are characterized by an insignificant density anomaly near the surface, could act as a barrier by trapping the surface waters and therefore sustaining the salinity anomalies. 

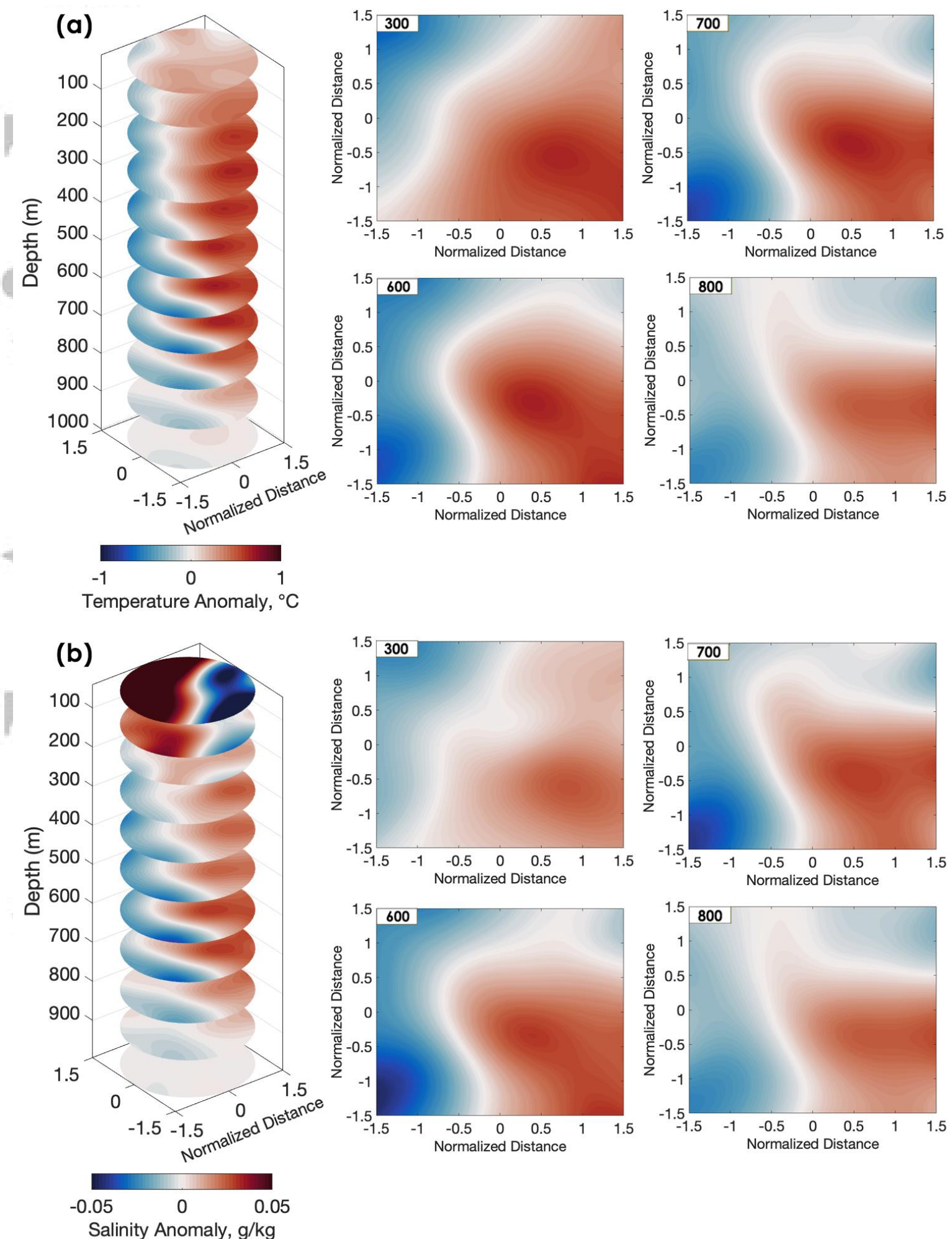

Figure 5. Three-dimensional temperature (a) and salinity (b) structure of the composite AE and horizontal distribution of temperature and salinity anomalies at the 300, 600, 700 and $800 \mathrm{~m}$.

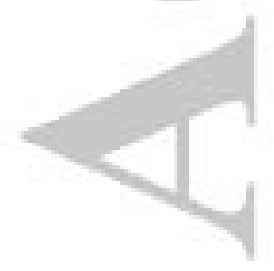



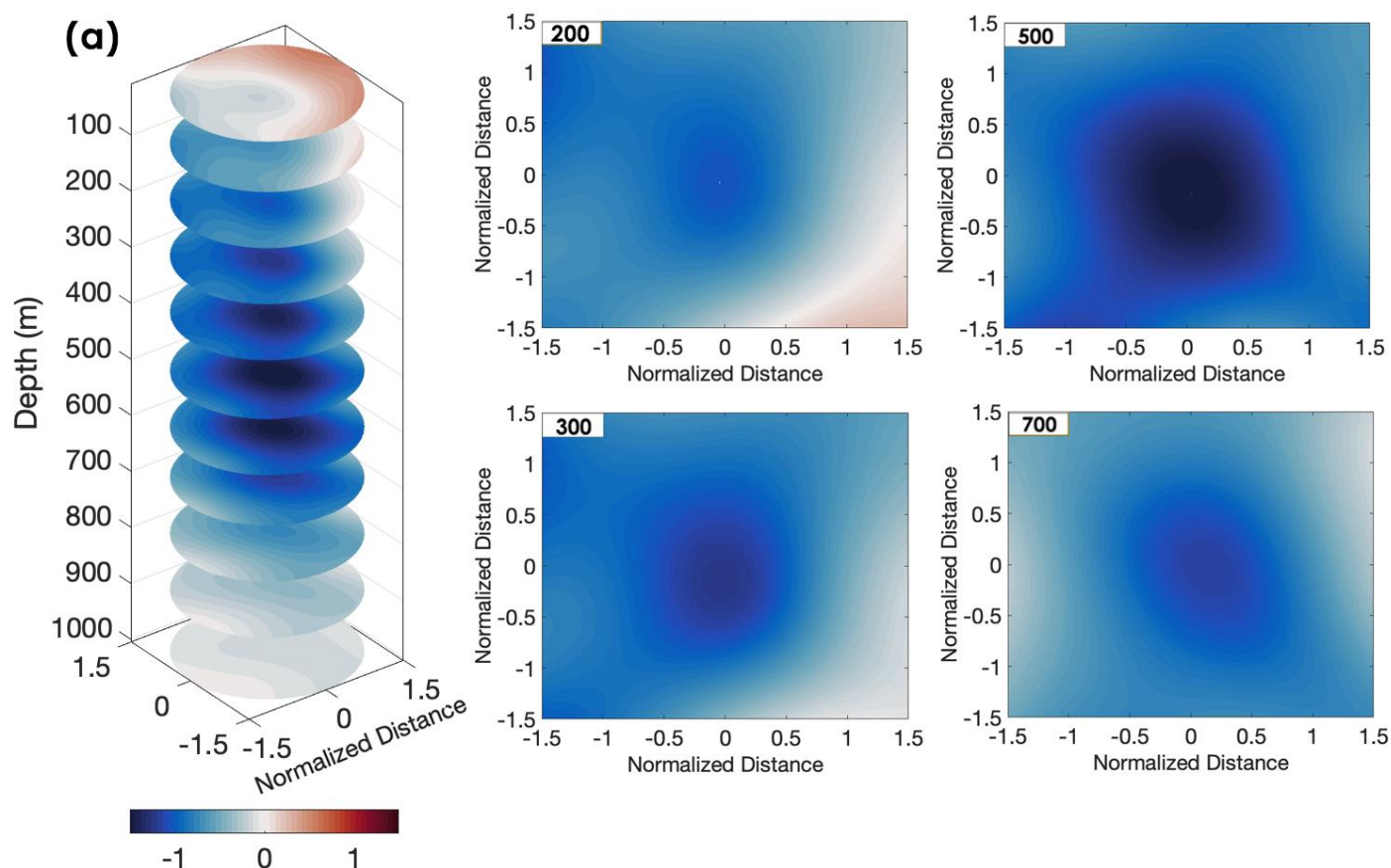

Temperature Anomaly, ${ }^{\circ} \mathrm{C}$
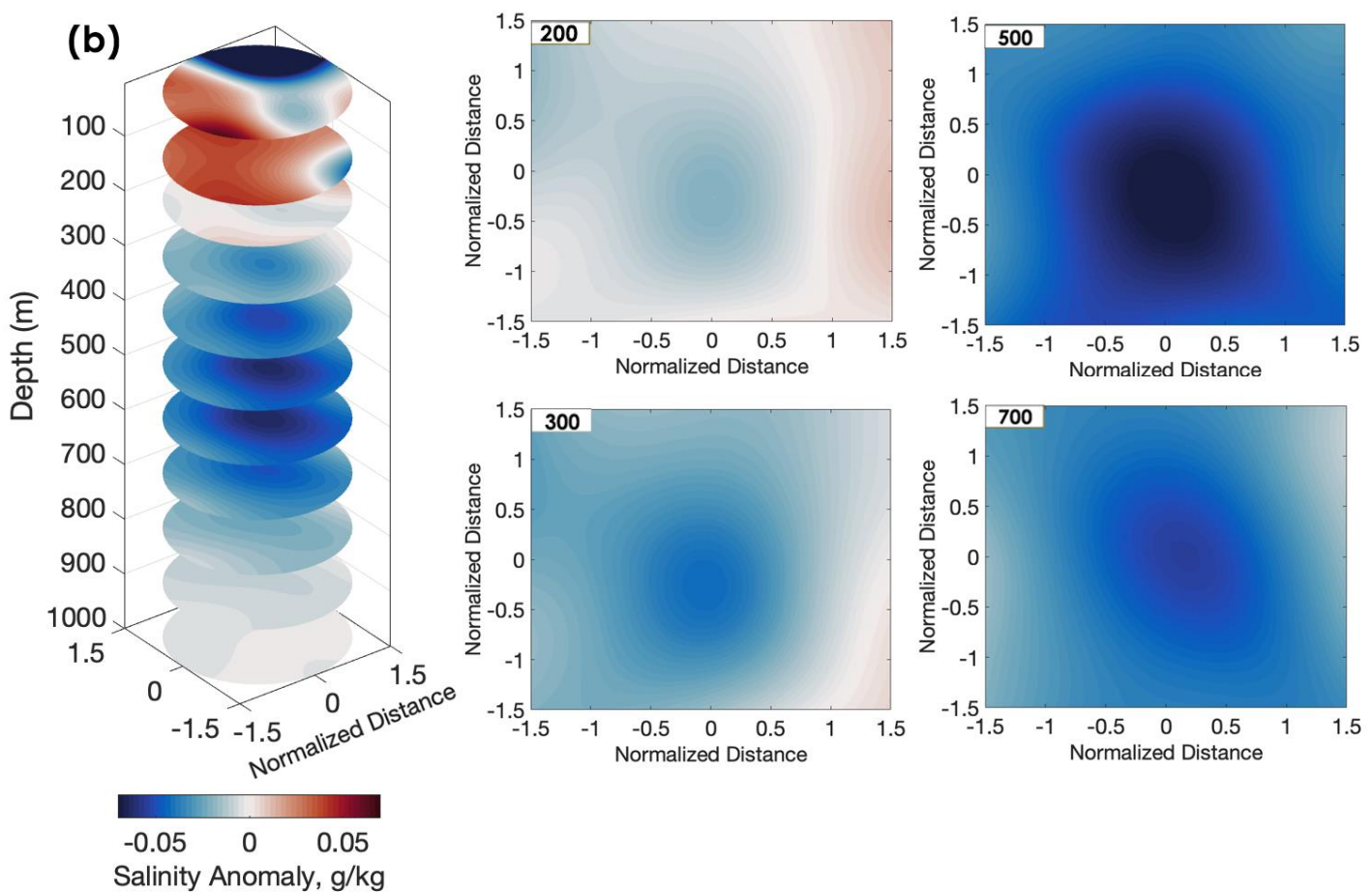

Salinity Anomaly, g/kg

Figure 6. Three-dimensional temperature (a) and salinity (b) structure of the composite CE and horizontal distribution of temperature and salinity anomalies at the 100, 300, 500 and $700 \mathrm{~m}$. 

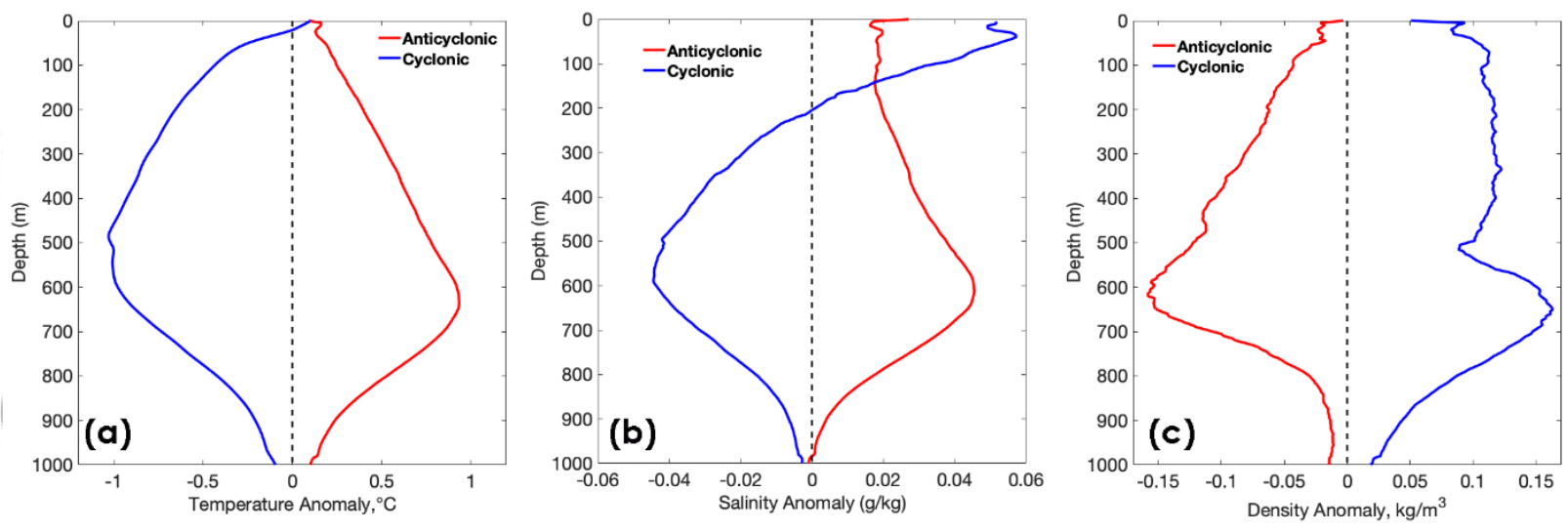

Figure 7. Mean vertical profiles of temperature (a), salinity (b) and density (c) anomalies averaged within $0.5 \mathrm{R}$ for the composite $\mathrm{AE}$ and $\mathrm{CE}$.

\subsection{Eddy-induced volume, heat and salt transports}

We use three-dimensional composites to estimate mass, heat and salt anomalies transported by AEs and CEs as well as the eddy contribution relative to heat and salt fluxes in the LB. The mean AEs radius $R$ is $55.2 \pm 19.4 \mathrm{~km}$ and $55.0 \pm 19.2 \mathrm{~km}$ for $\mathrm{CE}$ with an average vertical extent of $H \sim 930 \mathrm{~m}$ for both $\mathrm{AE}$ and $\mathrm{CE}$, so the mean eddy volume $V$ equals $(8.9 \pm 1.1)^{*} 10^{12} \mathrm{~m}^{3}$ for $\mathrm{AE}$ and $(8.8 \pm 1.07)^{*} 10^{12} \mathrm{~m}^{3}$ for CE (Table 1). According to the "Mesoscale Eddy Trajectory Atlas Product", the average propagation speed of mesoscale eddies $c$ in the Lofoten Basin equals $0.04 \pm 0.01 \mathrm{~m} / \mathrm{s}$ for eddies of both polarities. Taking into account those mean eddy parameters the volume transport $V_{t}$ for a single composite $\mathrm{AE}$ and $\mathrm{CE}$ can be calculated as:

$$
V_{t}=\frac{V c}{0.5 R}
$$

The total heat $(H C)$ and salt $(S C)$ contents transported by the composite AE and CE were calculated as follows (Chaigneau et al., 2011; Dong et al., 2017):

$$
\begin{aligned}
& H C=\rho C_{p} \int T^{\prime} d x d y d z \\
& S C=\rho \int S^{\prime} d x d y d z
\end{aligned}
$$

where $C_{p}=4,200 \mathrm{~J} \mathrm{~kg}^{-1} \mathrm{~K}^{-1}$ and $\rho=1,025 \mathrm{~kg} \mathrm{~m}^{-3}$ are specific heat capacity of the seawater and mean upper ocean density respectively; $T^{\prime}$ is the eddy-induced temperature anomaly, $S^{\prime}$ is the 
eddy-induced salinity anomaly. The integration limits are defined as $H$ and R. Notice that $H C$ and $S C$ transports are generally positive for $\mathrm{AE}$ and negative for $\mathrm{CE}$ (Table 1). As a result of larger temperature anomalies, the composite $\mathrm{CE}$ has 1.4-1.5 times more impact on the thermohaline fields in the LB than the composite AE (Table 1).

Table 1. Characteristics of a composite $\mathrm{AE}$ and $\mathrm{CE}$

\begin{tabular}{|l|l|l|}
\hline & \multicolumn{1}{|c|}{$\mathrm{AE}$} & \multicolumn{1}{c|}{$\mathrm{CE}$} \\
\hline $\begin{array}{l}\text { The average annual number } \\
\text { of individual eddies in the LB } \\
\text { region }\end{array}$ & 26 & 23 \\
\hline Volume $\left(10^{12} \mathrm{~m}^{3}\right)$ & $8.9 \pm 1.1$ & $8.8 \pm 1.1$ \\
\hline $\mathrm{HC}\left(10^{19} \mathrm{~J}\right)$ & $2.2 \pm 0.8$ & $-3.2 \pm 1.1$ \\
\hline $\mathrm{SC}\left(10^{11} \mathrm{~kg}\right)$ & $1.8 \pm 0.6$ & $-1.6 \pm 0.5$ \\
\hline Volume transport $(\mathrm{Sv})$ & $4.1 \pm 0.7$ & $4.0 \pm 0.7$ \\
\hline Heat transport $\left(10^{13} \mathrm{~W}\right)$ & $1.9 \pm 0.7$ & $-2.5 \pm 0.9$ \\
\hline Salt transport $\left(10^{5} \mathrm{~kg} / \mathrm{s}\right)$ & $1.5 \pm 0.5$ & $-1.2 \pm 0.4$ \\
\hline
\end{tabular}

\subsection{Time-mean Eddy-induced Volume Transport}

The mean eddy induced zonal and meridional transports in the LB are estimated in $1^{\circ} \times$ $0.35^{\circ}$ bins (excluding the LV area) using the method described in section 3 (Figure 8). The eddy-induced zonal transport (Fig. 8a) has a general westward direction with an average magnitude of $0.46 \mathrm{~Sv} / \mathrm{deg}^{2}$ for the whole study region. The zonal eddy-induced transport is significantly strengthened in the northeastern part of the study area with maximum values of $3.95 \mathrm{~Sv} / \mathrm{deg}^{2}$. It is weakened in the southeastern part of the basin, where the values of the zonal transport are close to zero. The eastward transport appear in the western area of the LB controlled by the NwAFC dynamics (Bosse \& Fer, 2019a). Here, the intensity of eastward transport reaches $1.26 \mathrm{~Sv} / \mathrm{deg}^{2}$.

The patterns of the geographical distribution of eddy induced meridional transport is more complex than zonal transport (Figure 8b). There are several significant characteristics worth noting. The northward transport takes place predominantly in the southern and eastern parts of the study region along the NwASC flows. It should also be noted that there is an area in the north-east of the LB within the longitude band $9^{\circ}-14^{\circ} \mathrm{E}$ where southward transport also prevails.

By estimating fluxes of heat and salt across the contour enclosing the central part of the LB, we can evaluate the amount of heat and salt which propagates toward the LB center and thereby potentially affecting the LV, as eddy induced heat/salt transport by mesoscale eddies and eddy mergers were identified as important mechanisms for the LV stability and longevity. We 
defined this border as the contour of the $2800 \mathrm{~m}$ isobath (Fig. 8). Based on data from the "Mesoscale Eddy Trajectory Atlas Product" the total number of mesoscale eddies crossing the $2800 \mathrm{~m}$ isobath contour in/out is 131/104 for the AEs and 105/87 for the CEs. This corresponds to a net transport of 27 AEs and 18 CEs within that contour during the period 2000-2017. The evaluations of the total heat and salt transports induced by AEs and CEs inside the area bounded by the $2800 \mathrm{~m}$ isobath are presented in Table 2 . The advection of heat or salt into the LV area has a slightly positive balance since the inflow of the heat or salt transported by eddies exceeds the outflow. It seems that most of the heat and salt transports induced by AEs is compensated by CEs, but other mechanisms are important for the fate of these eddy-induced transports, e.g. turbulent transfers to the atmosphere or the ocean interior. Based on the study Segtnan et al. (2011), our estimated transport across the contour of $2800 \mathrm{~m}$ isobath of $1 \mathrm{TW}$ is about $3.3 \%$ of the residual heat transport over the whole area of the eastern Nordic Seas.

Table 2. Annual heat and salt eddy-induced transports across the contour of $2800 \mathrm{~m}$ isobath

\begin{tabular}{|l|l|l|}
\hline & \multicolumn{1}{|c|}{ AEs } & \multicolumn{1}{c|}{ CEs } \\
\hline $\begin{array}{l}\text { Annual eddy heat transport } \\
\left(10^{12} \mathrm{~W}\right)\end{array}$ & $1.05 \pm 0.37$ & $-1.01 \pm 0.35$ \\
\hline $\begin{array}{l}\text { Annual eddy salt transport } \\
\left(10^{3} \mathrm{~kg} / \mathrm{s}\right)\end{array}$ & $8.41 \pm 2.94$ & $-4.91 \pm 1.71$ \\
\hline
\end{tabular}

The origin and mechanisms of CEs generation have not clearly been identified yet, whereas NwASC has been identified as an important source for AEs generation (Rossby et. al., 2009a; Isachsen et al., 2012; Raj et al., 2016; Trodahl \& Isachsen, 2019; Zinchenko et al., 2019). Considering the daily average number of AEs observed inside the $2800 \mathrm{~m}$ isobath $(0.8)$ and a turnover rate given by the inverse of the mean $\mathrm{AE}$ lifetime (34.3 days), the heat transported by composite AEs into the $\mathrm{LB}$ center would represent an average value of $38 \mathrm{~W} \mathrm{~m}^{-2}$, compensating for about half of the annual net heat loss to the atmosphere in the area reported by previous studies (Isachsen et al., 2012; Richards \& Straneo, 2015; Yu et al., 2017; Bosse et al., 2019). Note that this number might be underestimated, as eddies smaller than about $30 \mathrm{~km}$ radius are not well detected by satellite, but could still be major players of the heat convergence toward the Lofoten Basin (e.g. Richards \& Straneo, 2015; Isachsen et al., 2012; Lundrigan \& Demirov, 2019) reported from moored instruments in the Lofoten Basin mesoscale eddies with a mean radius of $17.4 \pm 9.0 \mathrm{~km}$ corresponding to about $25 \mathrm{~km}$ zero vorticity radius. 


\subsection{Zonal and meridional eddy volume transport}

The eddy-induced zonal and the meridional transports in the area enclosed by the boundary of $2800 \mathrm{~m}$ isobath is mainly westward along the northern and eastern boundaries of the LV area and eastward along the south-western boundary. A general northward transport is observed at the southern and eastern boundaries and southward transport at the northern and western boundaries of the LV region. This pattern of the eddy propagation agrees well with the counterclockwise eddy spiraling around the LB center (Volkov et. al., 2013, 2015) and a recent study highlighting the connection of AW from south across the outer rim of the Vøring Plateau (Dugstad et al., 2019).
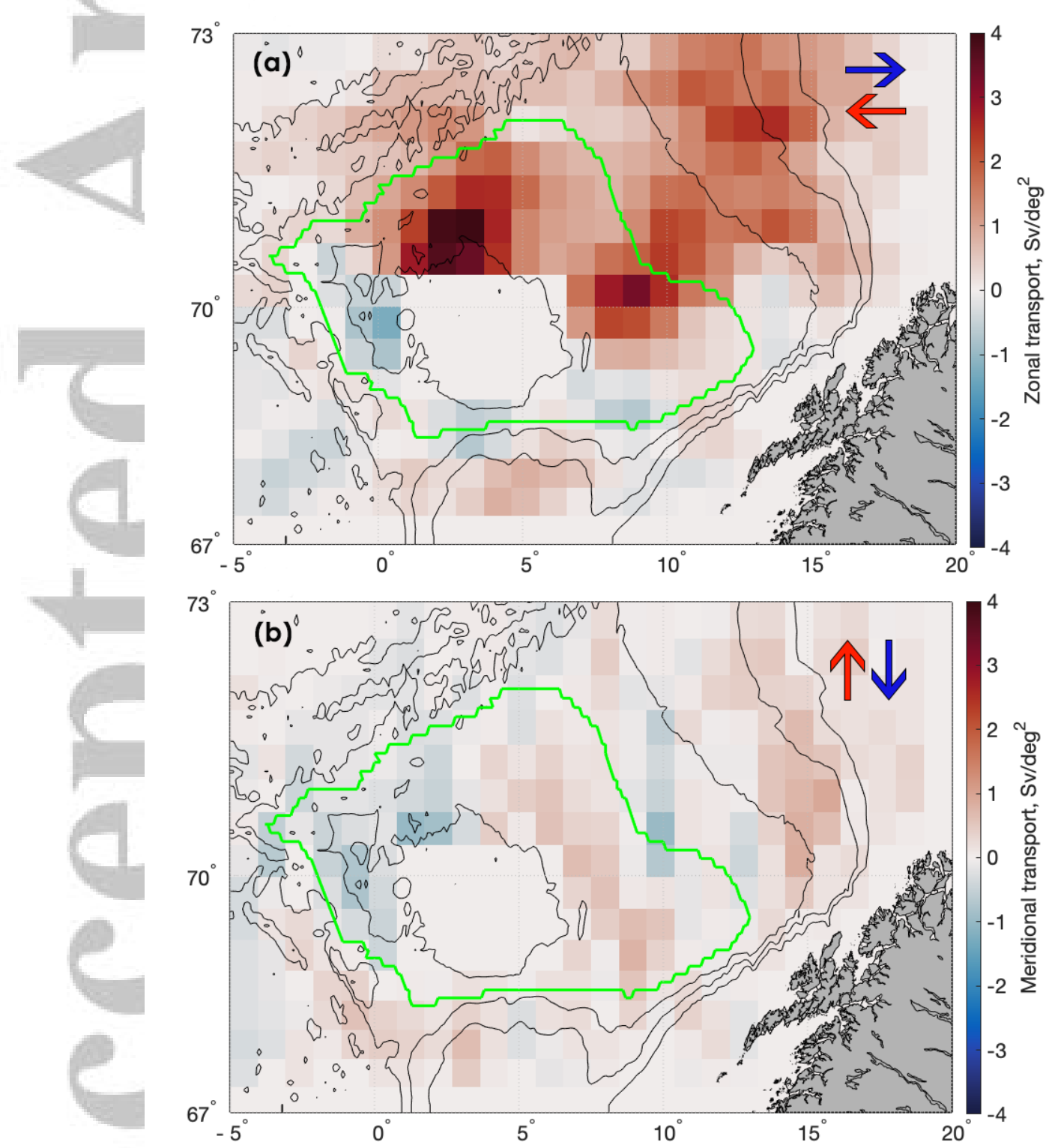

Figure 8. (a) Zonal and (b) meridional eddy volume transport calculated for every $1^{\circ} \times 0.35^{\circ}$ bin in the Lofoten Basin region (except the Lofoten Vortex area). The positive value refers to the westward (northward) transport, the negative value refers to the eastward (southward) transport. The green contour indicates the $2800 \mathrm{~m}$ isobath enclosing the central part of the LB. 
Figure 9 shows the meridionally (resp., zonally) integrated zonal (resp., meridional) volume transport induced by the mesoscale eddies in the LB region. The largest westward transport is observed in the longitude bands $9^{\circ}-12^{\circ} \mathrm{E}$ (Figure 9a) and over the whole LB the eddy-induced volume transport is westward except in the westernmost part of the region (longitude band 5-1W). It is consistent with results of several studies highlighting greatest eddy activity in the eastern part of the basin due to instability of the NwASC (Köhl, 2007; Rossby et. al., 2009a; Isachsen et al., 2012; Søiland \& Rossby, 2013; Raj et al., 2016; Trodahl \& Isachsen, 2019; Zinchenko et al., 2019). In general, the zonal component of transports induced by AEs exceeds that induced by CEs which is not surprising as the number of individual AEs identified in the LB exceeds the number of individual CEs. Note that the total eddy-induced zonal volume transports is westward except for the western part of the study region (longitude band $5^{\circ}-1^{\circ} \mathrm{W}$ ) where mesoscale eddies can be generated by instability of the NwAFC.

The distribution of the zonally integrated meridional volume transport is more complex (Figure $9 \mathrm{~b}$ ) and can be divided into three distinct areas with northward transport south of $69^{\circ}$ $\mathrm{N}$ and north of $70.8^{\circ} \mathrm{N}$ respectively, and southward eddy transport between $70.2^{\circ} \mathrm{N}$ and $70.5^{\circ}$ N. The overall northward transport induced by the LB eddies reaches the maximum value around $68^{\circ} \mathrm{N}$. It must be noted that north of $72^{\circ} \mathrm{N}$ the meridional transport for AE is northward while CE transport is southward.

The patterns of eddy-induced volume transport are closely related to the distribution and propagation of eddies in the LB region. The predominance of the volume transport induced by westward propagating eddies throughout the LB region confirms the crucial role of mesoscale eddies forming in the western part of the basin along the NwASC flow. The westward zonal transport can also be larger due to the comparatively larger eddies forming near the NwASC than those forming in the eastern part along the NwAFC in particular (Raj \& Halo, 2016). From the distribution of the eddy-induced zonal volume transport (Figure 8a) we can assume that the zonal westward eddy-induced transport contributes significantly to the general transport of heat and salt in the study region. The eastward transport is likely associated with eddy shed from the NwAFC, however, it can also be influenced by westward propagating eddies recirculating back to the east following the topographic contours.

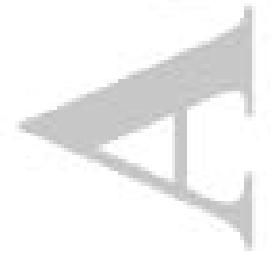



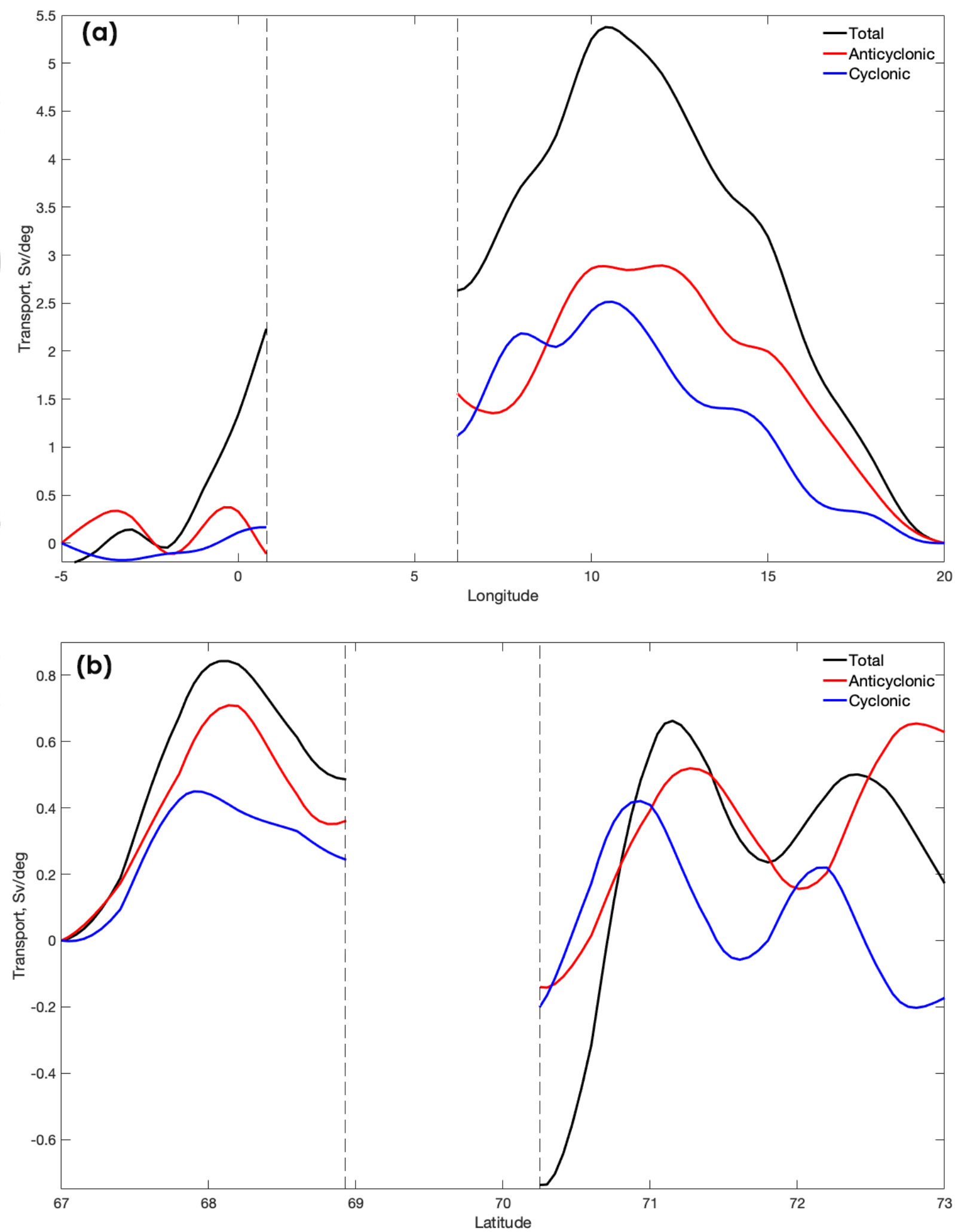

Figure 9. (a) Meridionally integrated zonal volume transport and (b) zonally integrated meridional volume transport in the Lofoten Basin region (except the Lofoten Vortex area). The area bounded by the dashed line corresponds to the LV region. 


\section{Summary and conclusion}

By using the updated version of the eddy dataset distributed by AVISO+ and applying a method of colocalization of in situ observations, we obtained detailed three-dimensional structures of composite $\mathrm{AE}$ and $\mathrm{CE}$ in the Lofoten Basin. The general structure of cyclonic and anticyclonic eddies reveals significant thermohaline anomalies concentrated within a distance of one radius (defined by zero vorticity contour) and extending vertically to the depth of $\sim 900-1000 \mathrm{~m}$. A key difference between CEs and AEs was found in terms of salinity and density anomalies in the upper layer.

The temperature and salinity anomalies in the AEs reach $1.0^{\circ} \mathrm{C}$ and $0.05 \mathrm{~g} / \mathrm{kg}$ respectively at $600 \mathrm{~m}$ and concentrate within the depth range of 150-900 m. Radial sections of density anomalies for the composite eddies closely follow the distribution of temperature anomalies with density anomalies in composite $\mathrm{AE}$ of $-0.15 \mathrm{~kg} / \mathrm{m}^{3}$ at $\sim 500 \mathrm{~m}$. In general, the thermohaline structure of eddies in the LB is more influenced by temperature contributing to more than $90 \%$ to the density anomalies.

The deep thermohaline structure of the CEs shows a similar pattern yet with negative values for temperature and salinity anomalies and positive for density. The core of the composite $\mathrm{CE}$ is located within the layer $300-600 \mathrm{~m}$ with a negative peak at $500 \mathrm{~m}$. The minimum temperature anomaly equals $-1.2{ }^{\circ} \mathrm{C}$ and salinity anomalies reach $-0.06 \mathrm{~g} / \mathrm{kg}$. In contrast with the composite AE, the composite CE exhibits a "dipole-like" structure in the vertical salinity distribution with positive anomalies in the upper layer resulting in a positive density anomaly reaching the surface with values of $0.1 \mathrm{~kg} / \mathrm{m}^{3}$. A possible explanation for this phenomenon is an outcropping of isopycnals in the CEs which could act as a barrier by trapping the surface waters and therefore sustaining the salinity anomalies.

A prominent feature of mesoscale eddies was revealed in spatial distributions of thermohaline anomalies inside obtained composite structures. AEs in the LB are warmer and saltier in their southwest compared to their northeast side. Similarly, CEs are colder and less salty in their southeast side. This particular feature of mesoscale eddies in the LB likely reflects features of the large-scale temperature and salinity gradients which are strongly affected by the warm and salty flow of the Norwegian Atlantic Slope Current. However, the observed pattern of the east-west gradient in the composite $\mathrm{AE}$ is not consistent with the spatial distribution of the temperature anomalies obtained within the borders of AEs. The temperature anomalies vary 
from the east $\left(\sim 0.5^{\circ} \mathrm{C}\right)$ to the west $\left(\sim 1^{\circ} \mathrm{C}\right)$ in the opposite direction as the background $\mathrm{AW}$ temperature.

Mean zonal eddy-induced transport is generally westward, significantly increasing and reaching a local maximum in the northeastern part of the study region. The predominance of the westward eddy-induced volume transport over the whole LB confirms the key role played by mesoscale eddies in the lateral heat and salt transfers from the NwASC toward the basin interior and their significant role in the general oceanic circulation of the LB.

Raj et. al. (2016) used a similar technique of colocation the Argo profiles and altimetry data to study the vertical structure of eddies in the LB region. In their work, they identified 55 and 45 profiles inside AEs and CEs respectively in the LB, but in contrast with our study, they used a much smaller data set of hydrographical profiles (only Argo floats) and didn't calculate climatological anomalies for the obtained profiles. They pointed out that the penetration depth of the AW is generally deepest inside AE reaching $1200 \mathrm{~m}$ for the individual profiles and salinity profiles inside the AEs showing deeper and well-mixed saline AW. Considering that they didn't exclude profiles inside the permanent and deep Lofoten Vortex, this can be a reasonable explanation for this large value. These results are generally in good agreement with our work.

With the present methodology, we are not able to subtract potential errors due to spatiotemporal gaps in the altimetric tracks sampling, as well as the influence of the seasonal and interannual variability of the basin properties, and internal waves.

The study of Lundrigan \& Demirov (2019) showed that the distribution of the eddy radii in the LB ranges between $19 \mathrm{~km}$ and $25 \mathrm{~km}$. Since the minimum radius from the Mesoscale Eddy Trajectory Atlas Product is $14 \mathrm{~km}$, we also take into account these eddies in our calculations. Moreover, the difference in the distribution of eddy sizes can be also caused by differences in the methods of the eddy detection.

As pointed out by $\mathrm{He}$ et al. (2018) the heat and salt transports calculated from the composite eddies and altimetry data do not consider diapycnal mixing with ambient waters. These problems can be further investigated by using oceanic model simulations. As mentioned in Keppler et. al (2018), this type of study can be of great use to track the eddy signature in shipborne CTD profiles or profiles made by ocean gliders. The obtained three-dimensional structures can be also used as a base for the future estimation of the impact of mesoscale eddies on the biogeochemical processes and environment in the LB region, as well as for validation of high-resolution climate and regional models. 


\section{Acknowledgements}

This research was supported by the Russian Science Foundation (project No. 18-17-00027). A.B. received funding from the Research Council of Norway, through the project "Water mass transformation processes and vortex dynamics in the Lofoten Basin of the Norwegian Sea (PROVOLO)" (project No. 250784). We thank Ilker Fer from University of Bergen, Norway for initiating the PROVOLO project that produced the dataset "Hydrography of the Nordic Seas, 2000-2017: A merged product". The dataset is publically available at https://doi.org/10.21335/NMDC-1131411242. We thank Aviso User Service for the dataset "Mesoscale Eddy Trajectory Atlas Product". The dataset is available at https://www.aviso.altimetry.fr/en/data/products/value-added-products/global-mesoscaleeddy-trajectory-product.html. The bathymetry dataset ETOPO 1 is available at http://dx.doi.org/10.7289/V5C8276M.
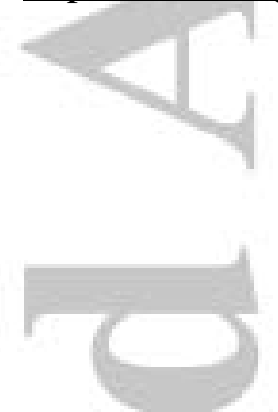

\section{References}

Alexeev, G.V., Bagryantsev, M.V., Bogorodsky, P.V., Vasin, V.B., \& Shirokov, P.E. (1991). Structure and circulation of water masses in the area of an anticyclonic vortex in the northeastern part of the Norwegian Sea. Russian problems of Arctic and Antarctic, 65, 14-23

Amante, C., \& Eakins B.W. (2009). ETOPO1 1 Arc-Minute Global Relief Model: Procedures, Data Sources and Analysis. NOAA Technical Memorandum NESDIS NGDC-24. National Geophysical Data Center, NOAA. doi:10.7289/V5C8276M

Andersson, M., Orvik, K. A., La Casce, J. H., Koszalka, I., \& Mauritzen, C. (2011). Variability of the Norwegian Atlantic Current and Associated Eddy Field from Surface Drifters. Journal of Geophysical Research, 116, C08032. doi:10.1029/2011JC007078

Argo (2020). Argo float data and metadata from Global Data Assembly Centre (Argo GDAC). SEANOE. http://doi.org/10.17882/42182

Årthun, M., Eldevik, T., Smedsrud, L. H., Skagseth, Ø., \& Ingvaldsen, R. B. (2012). Quantifying the Influence of Atlantic Heat on Barents Sea Ice Variability and Retreat. Journal of Climate 25, 4736-4743. doi:10.1175/JCLI-D-11-00266.1

Bashmachnikov, I., Belonenko, T., Kuibin, P., Volkov, D., \& Foux, V. (2018). Pattern of vertical velocity in the Lofoten vortex (the Norwegian Sea). Ocean Dynamics, 68, 1711-1725. https://doi.org/10.1007/s10236-018-1213-1 
Barnes, S. L. (1973). Mesoscale objective map analysis using weighted time-series observations (NOAA Tech. Memo. ERL NSSL-69, 60 pp.). Norman, OK: National Severe Storm Laboratory.

Belonenko, T.V., Koldunov, A.V., Sentyabov, E.V., \& Karsakov A.L. (2018). Thermohaline structure of the Lofoten vortex in the Norwegian sea based on field research and hydrodynamic modeling. Vestn S. Petersbur, Un-ta, 63 (4), 502519. https://doi.org/ 10.21638/spbu07.2018.406

Belonenko, T.V., Volkov, D.L., Ozhigin, V.K., \& Norden, Y.E. (2014). Circulation of waters in the Lofoten Basin of the Norwegian Sea. Vestn S. Petersbur. Un-ta, 7(2), 108-121

Björk, G., Gustafsson, B. G., \& Stigebrandt, A. (2001). Upper layer circulation of the Nordic seas as inferred from the spatial distribution of heat and freshwater content and potential energy. Polar Research, 20(2), 161-168. https://doi.org/10.1111/j.1751-8369.2001.tb00052.x

Bloshkina, E.V., \& Ivanov, V.V. (2016). Convective structures in the Norwegian and Greenland Seas based on simulation results with high spatial resolution. Proceedings of the Hydrometeorological Research Center of the Russian Federation, 361, 146-168

Bosse, A. \& Fer, I. (2018). Hydrography of the Nordic Seas, 2000-2017: A merged product https://doi.org/10.21335/NMDC-1131411242

Bosse, A., \& Fer, I. (2019a). Mean structure and seasonality of the Norwegian Atlantic Front Current along the Mohn Ridge from repeated glider transects. Geophysical Research Letters, 46, 13170 - 13179. https://doi.org/10.1029/2019GL084723

Bosse, A., \& Fer, I. (2019b) Seaglider missions in the Norwegian Sea during the PROVOLO project https://doi.org/10.21335/NMDC-980686647

Bosse, A., Fer, I., Lilly, J.M., \& Søiland, H. (2019). Dynamical controls on the longevity of a nonlinear vortex: The case of the Lofoten Basin Eddy. Sci Rep 9, 13448. https://doi.org/10.1038/s41598-019-49599-8

Bosse, A., Fer, I., Søiland, H., \& Rossby, T. (2018). Atlantic water transformation along its poleward pathway across the Nordic Seas. Journal of Geophysical Research: Oceans, 123, 6428-6448. https://doi.org/10.1029/2018JC014147

Chaigneau, A., Le Texier, M., Eldin, G., Grados, C., \& Pizarro, O. (2011). Vertical structure of mesoscale eddies in the eastern South Pacific Ocean: A composite analysis from altimetry and Argo profiling floats, J. Geophys. Res., 116, C11025. doi:10.1029/2011JC007134

Chelton, D.B., Gaube, P., Schlax, M.G., Early, J.J., Samelson, R.M. (2011b). The influence of nonlinear mesoscale eddies on near-surface oceanic chlorophyll. Science, 334(6054), 328-332. doi: $10.1126 /$ science. 1208897 . 
Chelton, D.B., Schlax, M.G., \& Samelson, R.M. (2011a). Global observations of nonlinear mesoscale eddies. Prog. Oceanogr, 91, 167-216.

Chafik, L., \& Rossby, T. (2019). Volume, heat, and freshwater divergences in the subpolar North Atlantic suggest the Nordic Seas as key to the state of the meridional overturning circulation. Geophysical Research Letters, 46, 4799-4808. https://doi.org/10.1029/2019GL082110

Dugstad, J. S., Koszalka, I. M., Isachsen, P. E., Dagestad, K.-F., \& Fer, I. (2019). Vertical structure and seasonal variability of the inflow to the Lofoten Basin inferred from high-resolution Lagrangian simulations. Journal of Geophysical Research: Oceans, 124, 9384-9403. https://doi.org/10.1029/2019JC015474

Dong, D., Brandt, P., Chang, P., Schutte, F., Yang, X., Yan, J., \& Zeng, J. (2017). Mesoscale eddies in the Northwestern Pacific Ocean: Three-dimensional eddy structures and heat/salt transports. Journal of Geophysical Research: Oceans, 122, 9795-9813. https://doi.org/10.1002/2017JC013303

Dong, C., McWilliams, J. C., Liu, Y., \& Chen, D. (2014). Global heat and salt transports by eddy movement. Nature Communications, 5, 3294. https://doi.org/10.1038/ncomms4294

Faghmous, J.H., Frenger, I., Yao, Y., Warmka, R., Lindell, A., \& Kumar, V. (2015). A daily global mesoscale ocean eddy dataset from satellite altimetry. Sci. Data, 2, 150028. Doi:10.1038/sdata.2015.28.

Falkowski, P.G., Ziemann, D., Kolber, Z.S., \& Bienfang, P. (1991). Role of eddy pumping in enhancing primary production in the ocean. Nature, 352, 55-58.

Fedorov, A. M., Bashmachnikov, I. L., \& Belonenko, T. V. (2019). Winter convection in the Lofoten Basin according to ARGO buoys and hydrodynamic modeling. Vestn S. Petersbur. Un-ta, Earth sciences, 64(3), 491-511. https://doi.org/10.21638/spbu07.2019.308

Fer, I., \& Bosse, A. (2017). Seaglider missions in the Lofoten Basin of the Norwegian Sea, 20122015 (Tech. rep.). Geophysical Institute, University of Bergen (Norway). https://doi.org/10.21335/NMDC-UIB.2017-00018

Fer I., A. Bosse, H. Søiland, B. Ferron \& P. Bouruet-Aubertot. (2019). Ocean currents, hydrography and microstructure data from PROVOLO cruises. https://doi.org/10.21335/NMDC$\underline{1093031037}$

Gaube, P., Chelton, D. B., Strutton, P. G., \& Behrenfeld, M. J. (2013). Satellite observations of chlorophyll, phytoplankton biomass, and Ekman pumping in nonlinear mesoscale eddies. J. Geophys. Res. Oceans, 118, 6349- 6370. doi:10.1002/2013JC009027

Gordeeva, S., Zinchenko, V., Koldunov, A., Raj, R. P., \& Belonenko, T. (2020). Statistical analysis of long-lived mesoscale eddies in the Lofoten basin from satellite altimetry. Advances in Space Research. doi:10.1016/j.asr.2020.05.043 
He, Q., Zhan, H., Cai, S., He, Y., Huang, G., \& Zhan, W. (2018). A new assessment of mesoscale eddies in the South China Sea: Surface features, three-dimensional structures, and thermohaline transports. Journal of Geophysical Research: Oceans, 123, 4906-4929. https://doi.org/10.1029/2018JC014054

Isachsen, P. E., Koszalka, I., Lacasce, J. H., Pedlosky, J., \& Häkkinen, S. (2012). Observed and Modeled Surface Eddy Heat Fluxes in the Eastern Nordic Seas. Journal of Physical Oceanography, 117, (8): 1-10. doi:10.1029/2012JC007935.

Ivanov, V.V., \& Korablev, A.A. (1995a). Formation and regeneration of the pycnocline lens in the Norwegian Sea. Russ. Meteorol. Hydrol., 9, 62-69.

Ivanov V.V., \& Korablev, A.A. (1995b). Dynamics of an intrapycnocline lens in the Norwegian Sea. Russ Meteorol Hydrol., 10, 55-62.

Jakobsen, P.K., Ribergaard, M.H., Quadfasel, D., Schmith, T., \& Hughes, C.W. (2003) Near-surface circulation in the northern North Atlantic as inferred from Lagrangian drifters: Variability from the mesoscale to interannual. J Geophys Res, 108 (C8)

Keppler, L., Cravatte, S., Chaigneau, A., Pegliasco, C., Gourdeau, L., \& Singh, A. (2018). Observed characteristics and vertical structure of mesoscale eddies in the southwest tropical Pacific. Journal of Geophysical Research: Oceans, 123, 2731-2756. https://doi.org/10.1002/2017JC013712

Köhl, A. (2007). Generation and stability of a quasi-permanent vortex in the Lofoten Basin. J Phys Oceanogr, 37, 2637-2651. doi:10.1175/2007JPO3694

Koszalka, I., La Casce, J.H., Andersson, M.K., Orvik, A., \& Mauritzen C. (2011). Surface circulation in the Nordic seas from clustered drifters. Deep Sea Res I, 58, 468-485. https://doi.org/10.1016/j.dsr.2011.01.007

Kubryakov, A.A., Bagaev, A.V., Stanichny, S.V., \& Belokopytov, V.N. (2018). Thermohaline structure, transport and evolution of the Black Sea eddies from hydrological and satellite data. Progress in Oceanography, 167, 44-63

Lundrigan, S., \& Demirov, E. K. (2019). Mean and eddy-driven heat advection in the ocean region adjacent to the Greenland-Scotland Ridge derived from satellite altimetry. Journal of Geophysical Research: Oceans, 124, 2239-2260. https://doi.org/10.1029/2018JC014854

Lozier, M. S., Bacon, F. Li, S., Bahr, F., Bower, A. S., Cunningham, S. A., de Jong, M. F., et al. (2019). A sea change in our view of overturning in the subpolar North Atlantic. Science, 363, 516-521. doi:10.1126/science.aau6592

Ma, J., Xu, H, Dong, C, Lin, P \& Liu, Y. (2015). Atmospheric responses to oceanic eddies in the Kuroshio Extension region. J. Geophys. Res. Atmos., 120, 6313-6330. doi: 10.1002/2014JD022930 
Mesoscale Eddy Trajectory Atlas Product Handbook, SALP-MU-P-EA-23126-CLS, issue 3.0 https://www.aviso.altimetry.fr/fileadmin/documents/data/tools/hdbk_eddytrajectory_META2 $\underline{018 . p d f}$

Mork, K.A., \& Skagseth, Ø. (2010). A quantitative description of the Norwegian Atlantic Current by combining altimetry and hydrography. Ocean Science, 6, 901-911. https://doi.org/10.5194/os6-901-2010, 2010

Pegliasco, C. A., Chaigneau, A \& Morrow, R. (2015). Main eddy vertical structures observed in the four major Eastern Boundary Upwelling Systems. J. Geophys. Res. Oceans, 120, 6008-6033, doi:10.1002/2015JC010950

Poulain, P.M., Warn-Varnas, A., \& Niiler, P.P. (1996). Near-surface circulation of the Nordic seas as measured by Largangian drifters. J Geophys Res, 101(C8), 18237-18258

Raj, R.P., Chafik, L., Even, J., Nilsen, O., Eldevik, T., \& Halo I. (2015). The Lofoten Vortex of the Nordic Seas. Deep Sea Res I, 96, 1-14. https://doi.org/10.1016/j.dsr.2014.10.011

Raj, R.P \& Halo, I. (2016). Monitoring the mesoscale eddies of the Lofoten Basin: importance, progress, and challenges. International Journal of Remote Sensing, 37:16, 3712-3728. doi: 10.1080/01431161.2016.1201234

Raj R.P., Johannessen J.A., Eldevik T., Nilsen J.E.Ø., \& Halo I. (2016). Quantifying mesoscale eddies in the Lofoten Basin. J Geophys Res, 121, 4503-4521. doi:10.1002/2016JC011637

Richards, C.G., \& Straneo, F. (2015). Observations of Water Mass Transformation and Eddies in the Lofoten Basin of the Nordic Seas. Journal of Phys Oceanogr, 45(6). doi:10.1175/JPO-D-140238.1

Rossby, T., Ozhigin, V., Ivshin, V., \& Bacon, S. (2009a). An isopycnal view of the Nordic Seas hydrography with focus on properties of the Lofoten Basin. Deep Sea Res I 56(11), 1955-1971

Rossby, T., Prater, M.D., \& Søiland, H. (2009b). Pathways of inflow and dispersion of warm waters in the Nordic seas. J. Geophys Res 114, C04011. doi:10.1029/2008JC005073

Sandø, A. B., Nilsen, J. E. Ø., Gao,Y., \& Lohmann, K. (2010). The Importance of Heat Transports and Local Air-Sea Heat Fluxes for the Barents Sea Climate Variability. Journal of Geophysical Research, 115, C07013. doi:10.1029/2009JC005884

Schlax, M. G. \& Chelton, D.B. (2016). The "Growing Method" of Eddy Identification and Tracking in Two and Three Dimensions. College of Earth, Ocean and Atmospheric Sciences, Oregon State University, Corvallis, Oregon, July 8, 2016

Simons, R. D., Nishimoto, M. M., Washburn, L., Brown, K. S., \& Siegel, D. A. (2015). Linking kinematic characteristics and high concentrations of small pelagic fish in a coastal mesoscale eddy. Deep Sea Research Part I: Oceanographic Research Papers, 100, 34-47. doi:10.1016/j.dsr.2015.02.002.

Skagseth, Ø., Slotte, A., Stenevik, E.K., \& Nash, R.D.M. (2015) Characteristics of the Norwegian Coastal Current during Years with High Recruitment of Norwegian Spring Spawning Herring 
$\begin{array}{lllll}\text { (Clupea harengus } \quad \text { L.). } & P L O S & \text { ONE } & 10(12), & \text { e } 0144117 .\end{array}$ https://doi.org/10.1371/journal.pone.0144117

Søiland, H., Chafik, L., \& Rossby, T. (2016). On the long-term stability of the Lofoten Basin Eddy, J Geophys Res, 121, 4438-4449. doi: 10.1002/2016JC011726

Søiland, H., \& Rossby, T. (2013). On the structure of the Lofoten Basin Eddy, J. Geophys. Res., 118, 4201-4212. doi:10.1002/jgrc.20301

Spall, M. A. (2010). Non-Local Topographic Influences on Deep Convection: An Idealized Model for the Nordic Seas. Ocean Modelling 32, 72-85. doi:10.1016/j.ocemod.2009.10.009

Segtnan, O. H., Furevik, T., \& Jenkins, A. D. (2011). Heat and freshwater budgets of the Nordic seas computed from atmospheric reanalysis and ocean observations. J. Geophys. Res., 116, C11003. doi: $\underline{10.1029 / 2011 J C 006939}$

Travkin, V. \& Belonenko, T. (2019). Seasonal variability of mesoscale eddies of the Lofoten Basin using satellite and model data. Russian Journal of Earth Sciences. 19. 1-10. doi:10.2205/2019ES000676.

Trodahl, M. \& Isachsen, P.E. (2018). Topographic Influence on Baroclinic Instability and the Mesoscale Eddy Field in the Northern North Atlantic Ocean and the Nordic Seas. J. Phys. Oceanogr., 48, 2593-2607. https://doi.org/10.1175/JPO-D-17-0220.1

Voet, G., Quadfasel, D., Mork, K. A., \& Søiland, H. (2010), The mid-depth circulation of the Nordic Seas derived from profiling float observations. Tellus Ser. A, 62(4), 516-529. doi:10.1111/j.1600-0870.2010.00444.x

Volkov, D.L., Belonenko, T.V., \& Foux, V.R. (2013). Puzzling over the dynamics of the Lofoten Basin - a sub-Arctic hot spot of ocean variability. Geophys Res Lett, 40 (4), 738-743. doi:10.1002/grl.50126

Volkov, D. L., Kubryakov, A. A., \& Lumpkin, R. (2015). Formation and Variability of the Lofoten Basin Vortex in a High-Resolution Ocean Model. Deep Sea Research, 105, 142-157. https://doi.org/10.1016/j.dsr.2015.09.001

Williams, S., Hecht, M., Petersen, M., Strelitz, R., Maltrud, M., Ahrens, J., Hlawitschka, M., \& Hamann, B. (2011). Visualization and analysis of eddies in a global ocean simulation. Comput. Graphics Forum, 30, 991-1000. https://doi.org/10.1111/j.1467-8659.2011.01948.x.

Willis, J. K., \& Fu, L.-L. (2008). Combining altimeter and subsurface float data to estimate the timeaveraged circulation in the upper ocean. $J$ Geophys Res, 113, C12017. doi:10.1029/2007JC004690

Yang, G., Wang, F., Li, Y., \& Lin, P. (2013). Mesoscale eddies in the northwestern subtropical Pacific Ocean: Statistical characteristics and three-dimensional structures. J. Geophys. Res. Oceans, 118, 1906-1925. doi:10.1002/jgrc.20164. 
Yu, L.-S., Bosse, A., Fer, I., Orvik, K. A., Bruvik, E. M., Hessevik, I., \& Kvalsund, K. (2017). The Lofoten Basin eddy: Three years of evolution as observed by Seagliders. J. Geophys. Res. Oceans, 122, 6814-6834. doi:10.1002/2017JC012982.

Yuan, Y. \& Castelao, R. M. (2017). Eddy-induced sea surface temperature gradients in Eastern Boundary Current Systems. J. Geophys. Res. Oceans, 122, 4791-4801, doi:10.1002/2017JC012735.

Zhang, Z., Zhang, Y., Wang, W., \& Huang, R.X. (2013). Universal structure of mesoscale eddies in the ocean. Geophys Res Lett, 40, 3677-3681. doi:10.1002/grl.50736, 2013

Zinchenko, V.A., Gordeeva, S.M., Sobko, Y.V., \& Belonenko, T.V. (2019). Analysis of Mesoscale eddies in the Lofoten Basin based on satellite altimetry. Fundamentalnaya i Prikladnaya Gidrofzika. 12 (3), 46-54. doi:10.7868/S2073667319030067

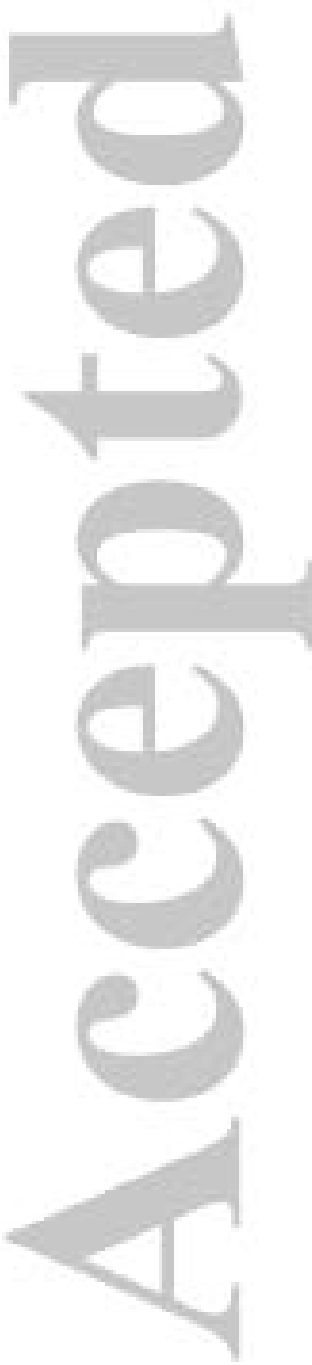

